\title{
Investigation and analysis of the influence of excitation signal on radiation characteristics of capacitive micromachined ultrasonic transducer
}

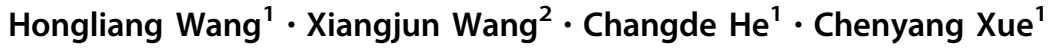 \\ Received: 30 October 2017 / Accepted: 1 February 2018/ Published online: 8 February 2018 \\ (C) The Author(s) 2018. This article is an open access publication
}

\begin{abstract}
CMUT based on micro-electro-mechanical systems technology has a significant advantage that traditional piezoelectric ultrasonic transducers do not have, and has become the mainstream transducer for the new generation of ultrasound imaging systems. In this paper, the state equation is deduced and the analysis model is established in SIMULINK environment based on the lumped parameter system model of the CMUT micro-unit. Through the state equationSIMULINK model, the influence of the parameters such as the DC bias voltage, the amplitude, frequency and period number of the AC excitation signal on the radiation characteristics is analyzed comprehensively. These results provide the important theoretical basis and reference for further optimization of structural design and application testing in the future.
\end{abstract}

\section{Introduction}

Compared with traditional piezoelectric ultrasonic transducers, The CMUT has significant advantages in improving bandwidth, improving imaging resolution, reducing size, reducing costs, achieving mass production and so on (Oralkan et al. 2002; Fouan and Bouakaz 2016; Sautto et al. 2017; Greenlay and Zemp 2017; Wang et al. 2014). And it has a broad application prospects in 3D medical ultrasound imaging (Bhuyan et al. 2013), intracardiac ultrasound detection (ICUS) (Nikoozadeh et al. 2009), intravascular ultrasound detection (IVUS) (Levent Degertekin et al. 2006), tissue harmonic imaging (THI) (Legros

Hongliang Wang

wanghongliang@nuc.edu.cn

Xiangjun Wang

xdocuxjw@vip.163.com

Changde $\mathrm{He}$

hechangde@foxmail.com

Chenyang Xue

xuechenyang@nuc.edu.cn

1 National Key Laboratory for Electronic Measurement Technology, Key Laboratory of Instrumentation Science and Dynamic Measurement, Ministry of Education, North University of China, Taiyuan 030051, China

2 MOEMS Education Ministry Key Laboratory, Tianjin University, Tianjin 300072, China et al. 2011), high intensity focused ultrasound (HIFU) treatment (Wong et al. 2007). More and more research institutions and companies in the world are carrying out the relevant research work.

As one of the key components of the ultrasound imaging system, the performance of the CMUT directly affects the quality of ultrasound imaging. And the performance of the internal CMUT micro-unit has a direct impact on the performance of the CMUT. In order to develop a CMUT that has good performance, the analysis of the CMUT characteristics is a very necessary part before processing, which can provide a basis for further optimization of design parameters. In the analysis of the characteristics, it is necessary to analyze the characteristics of the CMUT micro-unit from electrics, mechanics, acoustics and so on, and to consider various factors to obtain relatively optimized design parameters. There are many ways to analyze the characteristics of the CMUT micro-unit. At present, the common analysis models includes the equivalent circuit model (Lohfink and Eccardt 2005), the finite element analysis model (Yaralioglu et al. 2005), the finite difference model (Certon et al. 2005) and so on. These models make various analyses of the CMUT micro-unit with different analytic methods, which are with their own characteristics.

The initial equivalent circuit model was the small signal equivalent circuit model. It was the model that based on Mason's Equivalent Circuit Theory, which was the 
linearization of the plate capacitance model through the equivalent parameters of the lumped parameter system (Ladabaum et al. 1998). Then many scholars improved it, and the nonlinear equivalent circuit model and the large signal equivalent circuit model appeared (Koymen et al. 2012). The finite element analysis model can create $2 \mathrm{D}$ or 3D finite element models for vibrating films of any complex shape to obtain optimized design parameters by analysis and calculation, which is usually through ANSYS, COMSOL and other professional finite element analysis software. When the CMUT that contains many micro-units takes the finite element analysis model, the calculation process will be very time-consuming, which makes the simulation analysis and optimization design cycle longer (Satir et al. 2013). The finite difference model reduces the analysis time through thin plate theory and boundary element method. However, the current finite difference model cannot analyze the nonlinearity of CMUT micro-units, and not for large signals as well. Only the small signal linear model can be accurately analyzed (Satir et al. 2013).

In order to quickly and effectively analyze the characteristics of CMUT micro-units, The state equation of the system and its analysis model in the SIMULINK environment, which is called the state equation-SIMULINK model, are established in this paper by using the equivalent parameters of the lumped parameter system, which is based on the CMUT lumped parameter system model. The model can be analyzed for small signal models and can be analyzed for large signal models. The model can analyze both the small signal model and the large signal model. Then, a full range of the radiation characteristic analysis of CMUT micro-units is carried out by using the state equationSIMULINK model established in this paper, and the influence of different input excitation signals on the radiation characteristics is studied and analyzed. These results provide an important theoretical reference for CMUT structural optimization design and application testing in the future.

\section{The structure of the CMUT micro-unit and lumped parameter system model}

In general, the small vibration unit (referred to as microunit) that makes up the CMUT is usually composed of a metal upper electrode, a diaphragm, an edge support, a cavity, an insulating layer, a lower electrode and a base. The diaphragm is usually designed in circular, square, hexagonal and other regular shapes. Figure 1 shows the structure of the micro-unit with the circular diaphragm. In the figure, $r_{e}$ is the radius of the upper electrode, $r_{m}$ is the radius of the vibrating film, $t_{e}$ is the thickness of the upper and lower electrodes, $t_{m}$ is the thickness of the vibrating

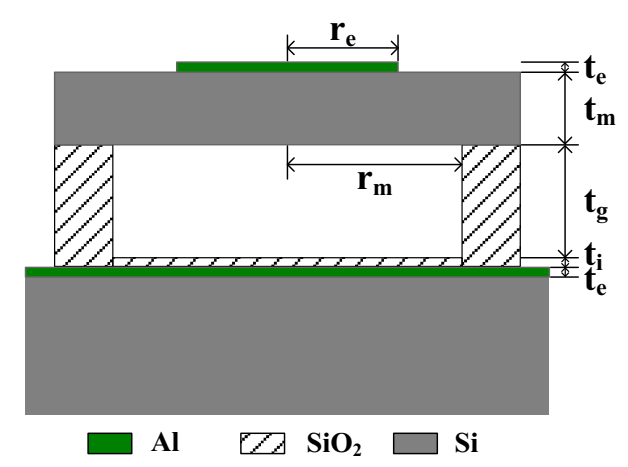

Fig. 1 The structure of the CMUT micro-unit

film, $t_{g}$ is the height of the cavity, and $t_{i}$ is the thickness of the insulating layer. Table 1 shows the main structure parameters of the CMUT micro-unit designed in this paper. Simultaneously, we find it that its natural frequency in air and water were $1.642 \mathrm{MHz}$ and $628 \mathrm{kHz}$, respectively, after model and analyze it through the COMSOL software.

For the structure of the CMUT micro-unit shown in Fig. 1, it can be described and analyzed by the lumped parameter system model consisting of a mass block, a spring and a damper as shown in Fig. 2. In the lumped parameter system model, the equivalent mass is $\mathrm{M}$, the elasticity coefficient is $\mathrm{K}$, the resistance coefficient is $\mathrm{R}$, the displacement of the vibration film is $\mathrm{w}$, and the external force acting on the CMUT micro-unit is F. The vibration equation as shown in Formula (1) is obtained based on Newton's second law. The calculation method of the equivalent mass $M$, the elastic coefficient $K$ and the resistance coefficient $R$ is described and illustrated in detail in literature (Wygant et al. 2008), so no more details here.

$M \frac{d^{2} w}{d t^{2}}+R \frac{d w}{d t}+K w=F$.

\section{The state equation-SIMULINK model of the CMUT in radiation state}

In fact, the lumped parameter system shown in Fig. 2 is a nonlinear system. Due to the nonlinearity of the electrostatic force $F_{e}$, the system state equation can be deduced based on Formula (1), and the system is built in SIMULINK environment, and then the system simulation and analysis are carried out directly to obtain more accurate analysis results.

When the CMUT is in the radiation state, the force acting on the CMUT is the electrostatic force Fe. Its expression can be easily obtained based on the plate capacitance model theory. Formula (2) can be obtained by substituting it into Formula (1). In the equation, $\varepsilon_{0}$ is the 
Table 1 Main design parameters of the CMUT micro-unit

\begin{tabular}{lllllll}
\hline Structure unit & \multicolumn{2}{l}{ Design parameters } & & \\
\cline { 2 - 6 } & $\begin{array}{l}\text { Radius } \\
(\mu \mathrm{m})\end{array}$ & $\begin{array}{l}\text { Thickness/height } \\
(\mu \mathrm{m})\end{array}$ & Materials & Young modulus $(\mathrm{GPa})$ & Poisson's ratio & Density $\left(\mathrm{kg} / \mathrm{m}^{3}\right)$ \\
\hline Film & 90 & 3 & $\mathrm{Si}$ & 169 & 0.299 & 2332 \\
Electrode & 45 & 0.2 & $\mathrm{Al}$ & 70 & 0.350 & 0.170 \\
Insulating layer & 90 & 0.1 & $\mathrm{SiO}_{2}$ & 72 & 2200 \\
Cavity & 85 & 0.7 & Vacuum & & 200 \\
\hline
\end{tabular}

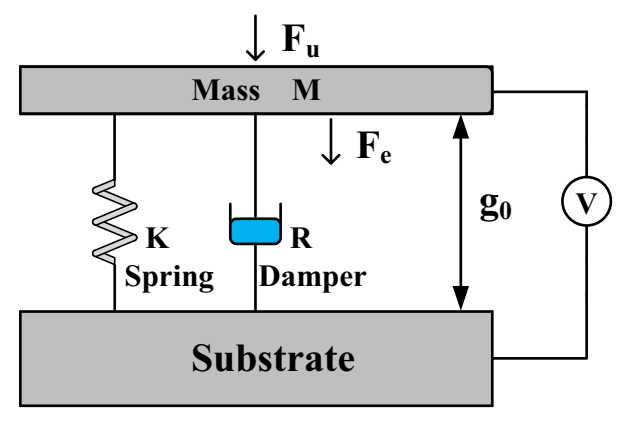

Fig. 2 The system model

vacuum dielectric constant, $\mathrm{A}$ is the effective area of the electrode, and $g_{0}$ is the initial distance between the upper and lower electrodes.

$M \frac{d^{2} w}{d t^{2}}+R \frac{d w}{d t}+K w=\frac{\varepsilon_{0} A V^{2}}{2\left(g_{0}-w\right)^{2}}$.

If we set $w_{1}=w, w_{2}=d w_{1} / d t$, the differential equation shown in Formula (2) can be transformed into the state equation as shown in Formula (3).

$\left\{\begin{array}{l}\dot{w}_{1}=w_{2} \\ \dot{w}_{2}=\frac{1}{M}\left[\frac{\varepsilon_{0} A V^{2}}{2\left(g_{0}-w_{1}\right)^{2}}-R w_{2}-K w_{1}\right] .\end{array}\right.$

It should be noted that the zero point of the displacement is the position at which the vibrating film is stationary and the positive direction is below the vibrating film in the plate capacitance model and the lumped parameter system model. Thus, the displacement curve plotted in the Cartesian coordinates is just opposite to the direction of the displacement of the vibrating film. In order to describe the change of the displacement of the vibrating film with time more intuitively, it is usually described by $-w$. And the electrostatic force becomes $-\mathrm{F}_{\mathrm{e}}$ with taking into account the directionality of the electrostatic force and set $w_{1}$ $=-w, w_{2}=d w_{1} / d t$. Thereby, the Formula (3) is transformed into the state equation shown in Formula (4).

$$
\left\{\begin{array}{l}
\dot{w}_{1}=w_{2} \\
\dot{w}_{2}=\frac{1}{M}\left[-\frac{\varepsilon_{0} A V^{2}}{2\left(g_{0}+w_{1}\right)^{2}}-R w_{2}-K w_{1}\right] .
\end{array}\right.
$$

For the state equations shown in Formulas (3) and (4), the numerical integration method can be used to solve them directly. Or the system module diagram can be constructed in SIMULINK environment, and then perform the system simulation analysis of them. In view of the nonlinearity of the electrostatic force, the system is divided into two parts: the nonlinear module (electrostatic force) and the linear module (CMUT vibration system) as the system model is being built. The electrostatic force Fe can be calculated through the nonlinear module, and the displacement and speed can be obtained based on the linear module. The CMUT transmits the acoustic signal to the external media, producing the sound pressure. The output sound pressure can be obtained by multiplying the vibration velocity of the CMUT film by its radiation resistance. Therefore the SIMULINK model of the CMUT micro-unit in the radiation state model can be established, as shown in Fig. 3. The nonlinear module (electrostatic force) is shown in Fig. 4, and linear module (CMUT vibration system) is shown in Fig. 5.

\section{Radiation characteristics analysis of the CMUT under different input signals}

Typically, the CMUT input voltage $\mathrm{V}$ contains a DC bias voltage $\mathrm{V}_{\mathrm{DC}}$ and an $\mathrm{AC}$ voltage signal, and the $\mathrm{AC}$ voltage signal can be represented by a sinusoidal signal. Then, the input voltage $\mathrm{V}$ can be expressed by Formula (5), and its square $V^{2}$ can be expressed by Formula (6), where $f_{s}$ represents the frequency of sinusoidal AC signal.

$$
\begin{aligned}
V & =V_{D C}+V_{A C} \sin \left(2 \pi f_{s} t\right) \\
V^{2} & =\left[V_{D C}+V_{A C} \sin \left(2 \pi f_{s} t\right)\right]^{2} \\
& =V_{D C}^{2}+\frac{1}{2} V_{A C}^{2}+2 V_{D C} V_{A C} \sin \left(2 \pi f_{s} t\right)-\frac{1}{2} V_{A C}^{2} \cos \left(4 \pi f_{s} t\right)
\end{aligned}
$$


Fig. 3 The SIMULINK model diagram of the CMUT microunit in the radiation state
Fig. 4 The nonlinear modules (electrostatic force) composition diagram
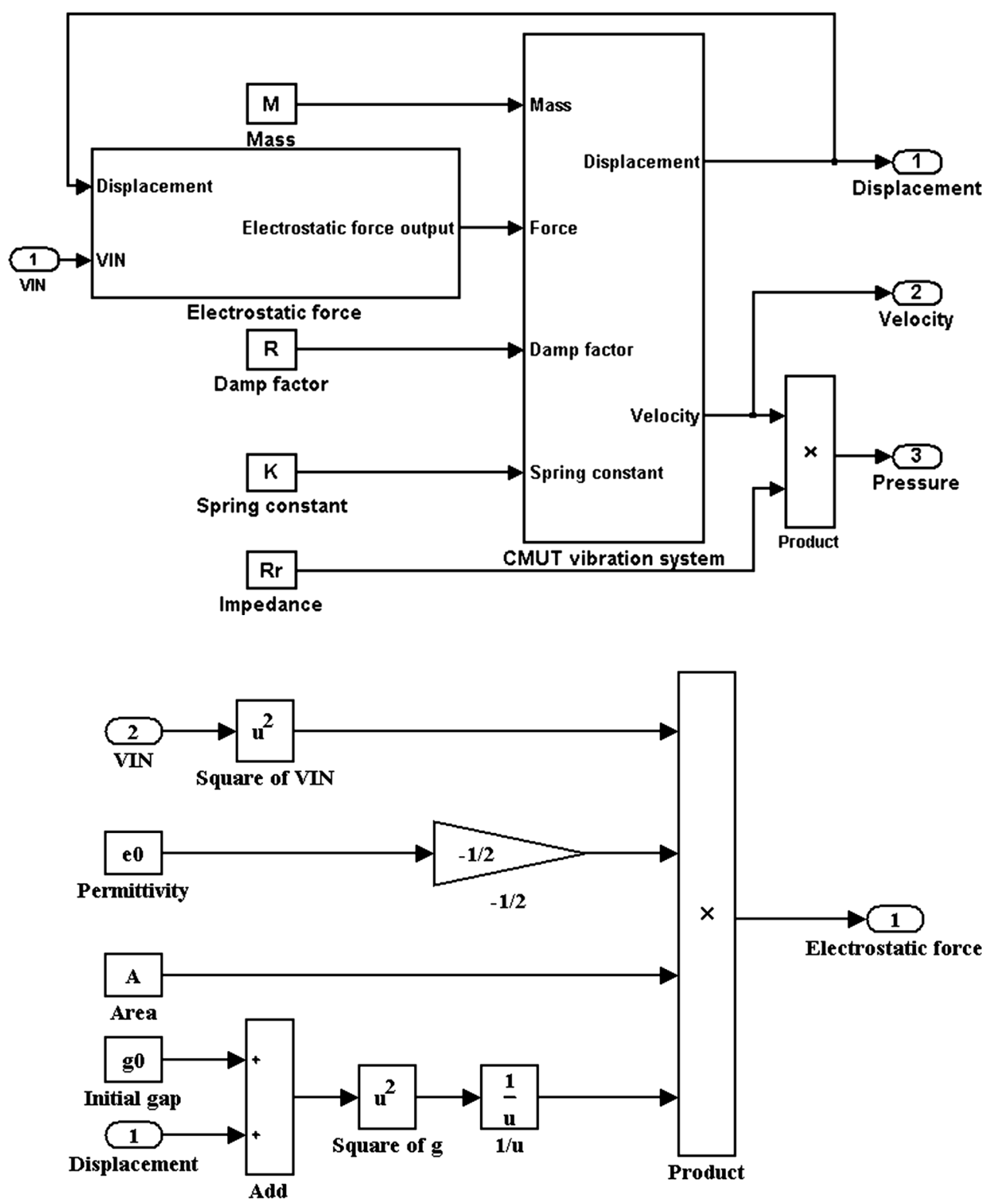

Formula (6) indicates that $\mathrm{V}^{2}$ also contains the sinusoidal signal with the frequency of $2 \mathrm{f}_{\mathrm{s}}$, besides the sinusoidal signal with the frequency of $f_{s}$. That is the second harmonic signal.

In this paper, the collapse phenomenon of the CMUT micro-unit under the water and the displacement and sound pressure characteristics of the CMUT micro-unit in different transmitted signals will be analyzed through the SIMULINK model for the CMUT micro-unit that was designed. In the analysis, set the effective range of displacement from $-\mathrm{g}_{0}$ to 0 . These analysis results will provide an important theoretical basis for the subsequent practical application and testing.

\subsection{Analysis of the collapse phenomenon}

According to the calculation formula of the collapse voltage $\mathrm{V}_{\mathrm{PI}}$ in literature (Ladabaum et al. 1998), it can be calculated that the collapse voltage of the CMUT microunit designed in this paper is about $134.13 \mathrm{~V}$. In order to verify its collapse phenomenon, three step functions of different amplitudes is selected as the input voltage of the CMUT micro-unit in the radiation state. Make the amplitudes of the step function jump respectively from 0 to $133.63,134.13,134.63 \mathrm{~V}$ at $1 \mathrm{~s}$. And observe the changes in vibration displacement respectively, as shown in Fig. 6 . It can be seen from the figure, when the input voltage is $133.63 \mathrm{~V}$, the maximum vibration displacement is about $0.21 \mathrm{~m}$. When the input voltage as the collapse voltage is 
Fig. 5 The linear module (CMUT vibration system) composition diagram

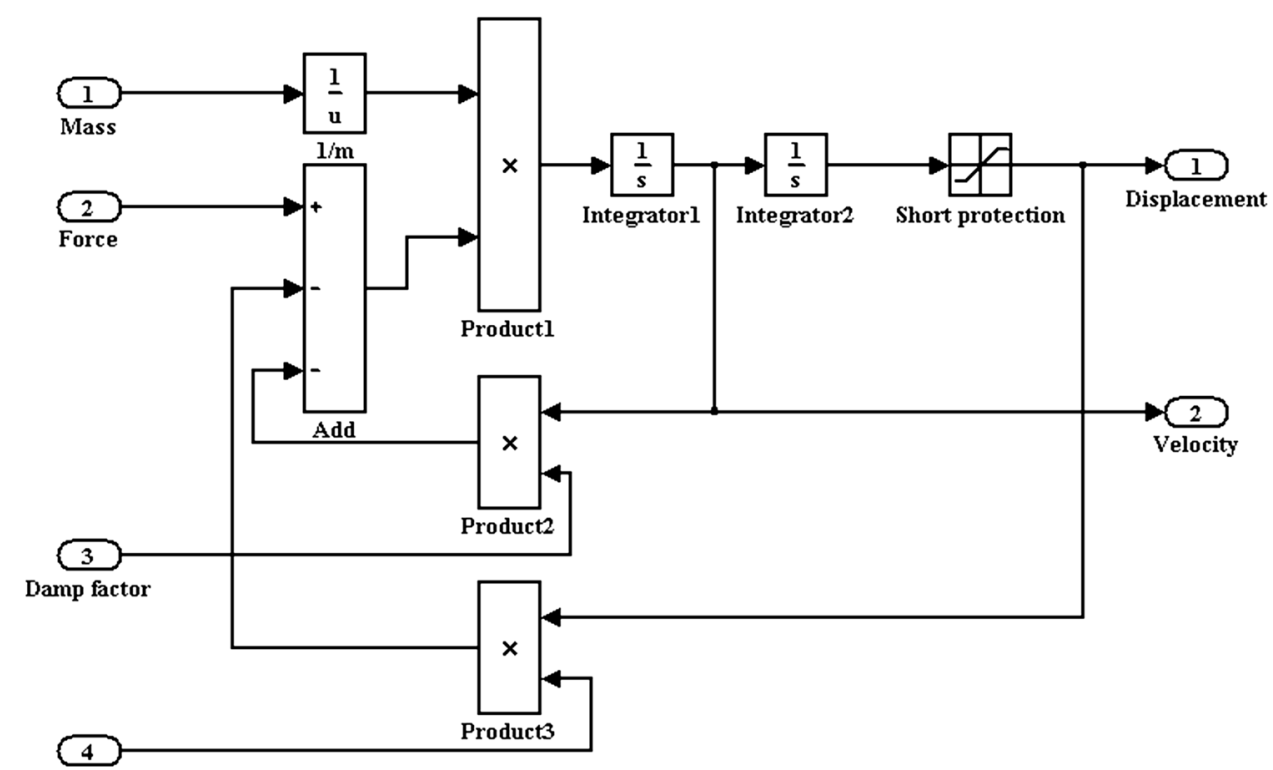

Spring constant

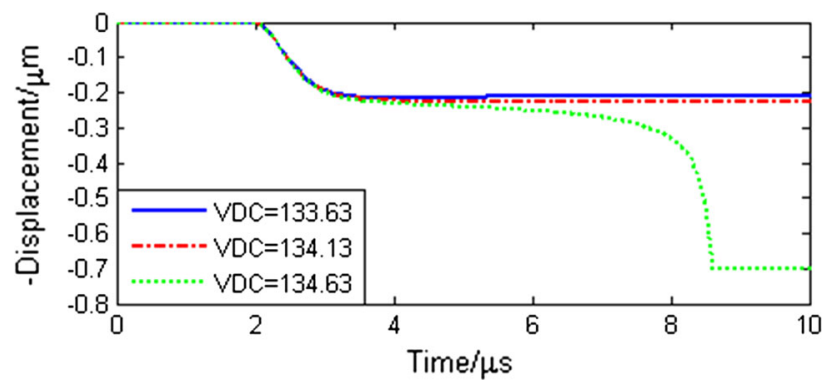

Fig. 6 The collapse phenomenon of the CMUT micro-unit

$134.13 \mathrm{~V}$, the maximum vibration displacement is about $0.23 \mathrm{~mm}$, which is one-third of the cavity height of $0.7 \mathrm{~mm}$. When the input voltage increases from the collapse voltage to $134.63 \mathrm{~V}$, the maximum vibration displacement is about $0.7 \mathrm{~mm}$, where it collapses to the bottom of the cavity. It should be noted that the impact of external pressure isn't taken into consideration in the analysis of the collapse phenomenon. In fact, due to the external pressure, the collapse voltage is lower than the theoretical value.

\subsection{Analysis of radiation characteristics with small $\mathbf{V}_{\mathrm{AC}}$}

First, for a specific AC signal of the small amplitude, as $\mathrm{V}_{\mathrm{AC}} \ll \mathrm{V}_{\mathrm{DC}}$, the influence of the DC bias voltage on the radiation characteristics of the CMUT micro-unit is analyzed by selecting the different amplitude of the DC bias voltage. The sinusoidal signal is selected as the AC input signal, and the amplitude is $2 \mathrm{~V}$, the frequency is $600 \mathrm{kHz}$, the duration is 5 periods. And the time domain waveform

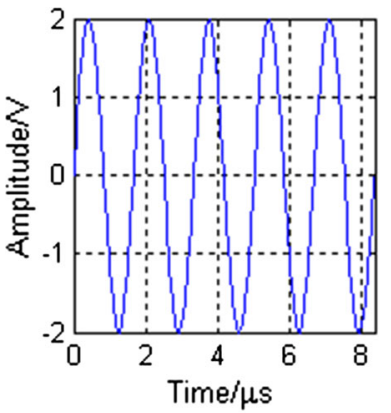

(a)

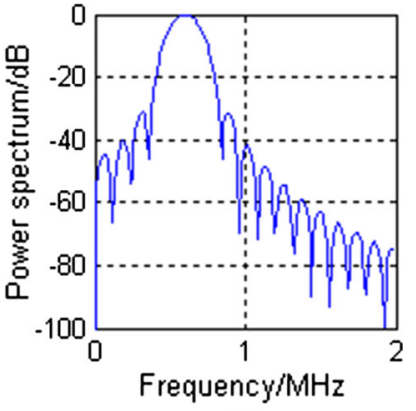

(b)
Fig. 7 AC input signal. a AC signal time domain waveform. b AC signal normalized power spectrum

and the normalized power spectrum of it are shown in Fig. 7a, b, respectively.

Respectively, select $0.1 \mathrm{~V}_{\mathrm{PI}}, 0.4 \mathrm{~V}_{\mathrm{PI}}, 0.7 \mathrm{~V}_{\mathrm{PI}}, 0.9 \mathrm{~V}_{\mathrm{PI}}$ as the DC bias voltage. The vibration displacement of the CMUT micro-unit is shown in Fig. 8a. The output sound pressure is shown in Fig. 8b, and the normalized power spectrum of the output sound pressure is shown in Fig. 9.

It can be seen from Fig. 8a, $b$ that as $\mathrm{V}_{\mathrm{AC}} \ll \mathrm{V}_{\mathrm{DC}}$, the vibration displacement of the CMUT micro-unit and the amplitude of the output sound pressure are related to the DC bias voltage. They increase as the DC bias voltage increases. Also, it can be seen obviously from Fig. 8a that the vibration range of the film expands as the DC bias voltage increases.

Figure $9 \mathrm{a}, \mathrm{b}$ indicate that the DC bias voltage affects the center frequency of the output sound pressure. When the DC bias voltage is $0.1 \mathrm{~V}_{\mathrm{PI}}$, the center frequency is about $654 \mathrm{kHz}$. When the $\mathrm{DC}$ bias voltage is $0.4 \mathrm{~V}_{\mathrm{PI}}$, the center frequency is about $644 \mathrm{kHz}$. When the DC bias voltage is 
Fig. 8 Changes in the vibration displacement and output sound pressure with the DC bias voltage changing as

$\mathrm{V}_{\mathrm{AC}} \ll \mathrm{V}_{\mathrm{DC}}$. a The vibration displacement. b The output sound pressure

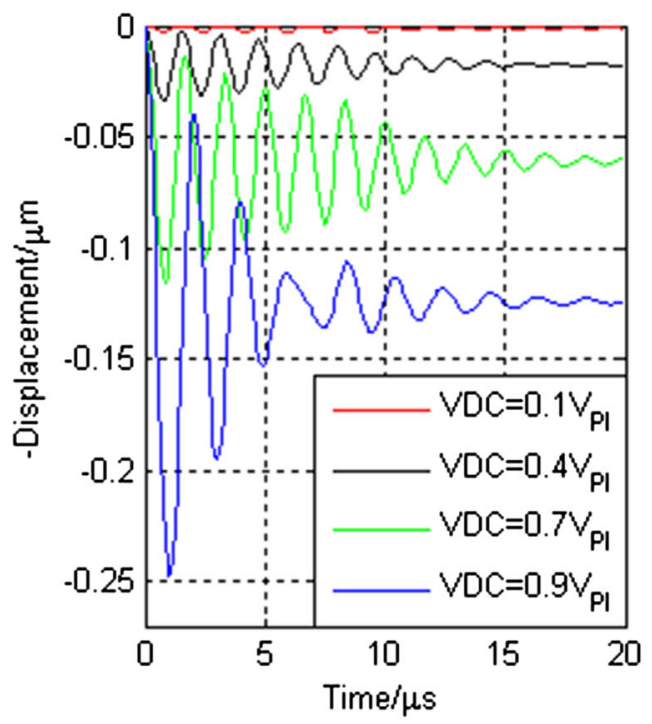

(a)

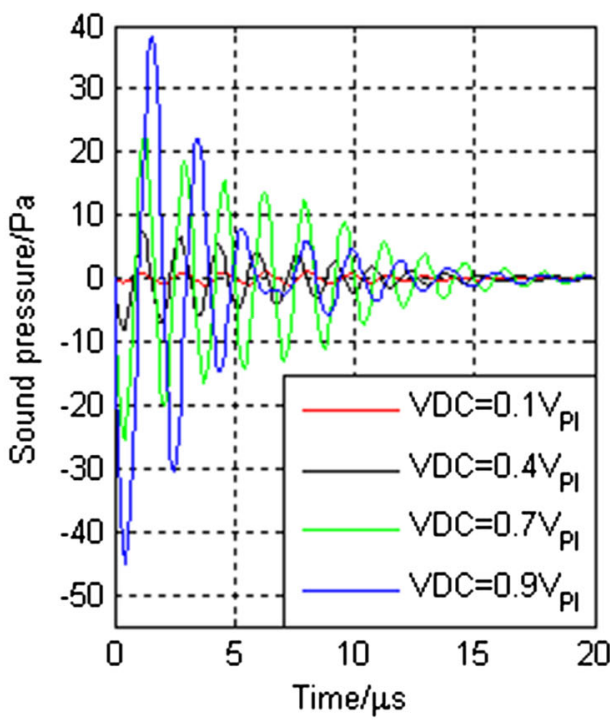

(b)
Fig. 9 The power spectrum of output sound pressure corresponding to different DC bias voltages as $\mathrm{V}_{\mathrm{AC}} \ll \mathrm{V}_{\mathrm{DC}}$. a Normalized linear power spectrum. b Normalized logarithmic power spectrum

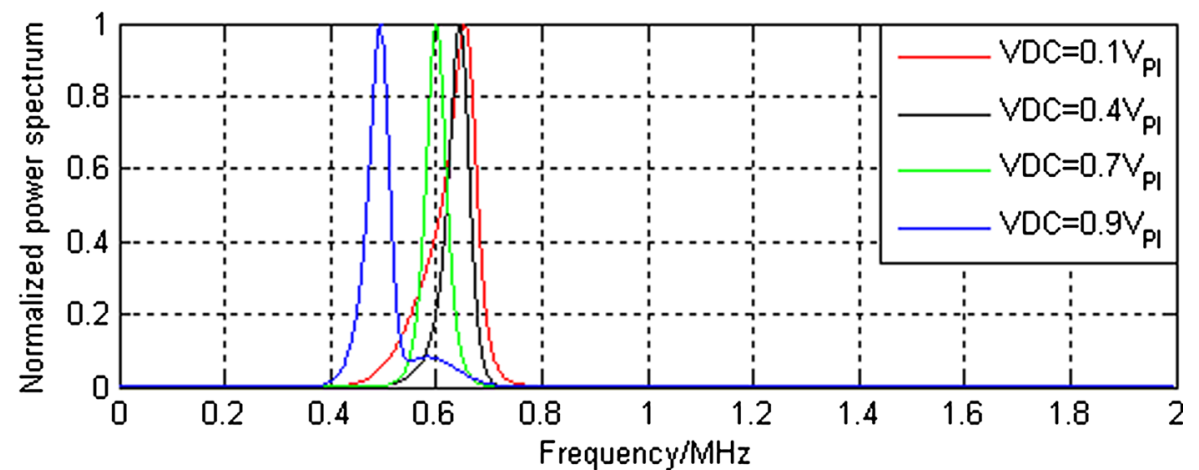

(a)

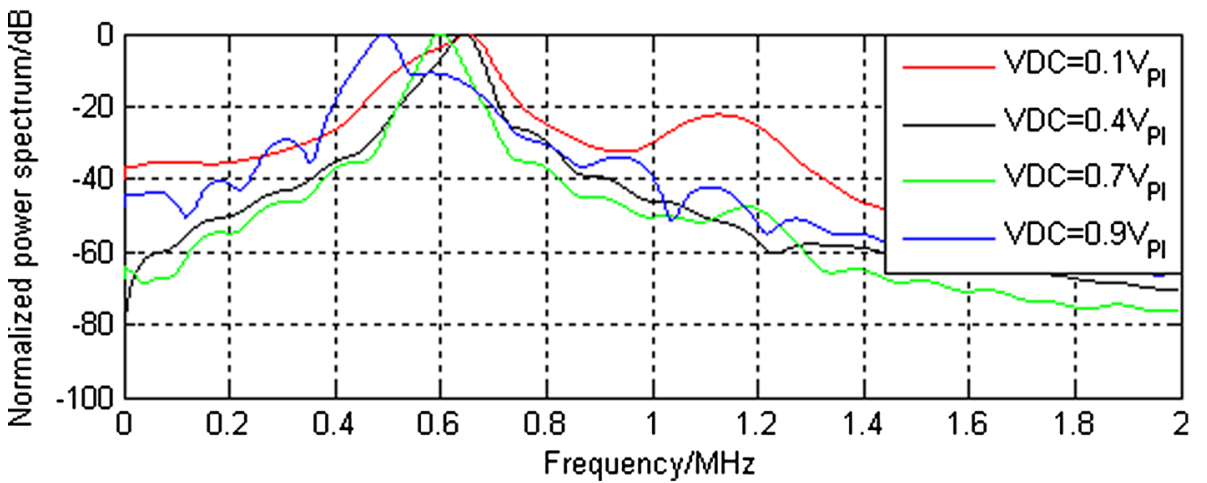

(b)
$0.7 \mathrm{~V}_{\mathrm{PI}}$, the center frequency is about $600 \mathrm{kHz}$. When the $\mathrm{DC}$ bias voltage is $0.9 \mathrm{~V}_{\mathrm{PI}}$, the center frequency is about $494 \mathrm{kHz}$. As the DC bias voltage increases, the center frequency will decrease. This is mainly due to the fact that the equivalent spring of the CMUT micro-unit has softened, causing the reduction in its equivalent elasticity coefficient.
Then, for a particular DC bias voltage, the influence of the amplitude of the AC signal on the radiation characteristics of the CMUT micro-unit is analyzed as $\mathrm{V}_{\mathrm{AC}}$ $\mathrm{V}_{\mathrm{DC}}$, by selecting the AC signals of different amplitudes. With $0.7 \mathrm{~V}_{\mathrm{PI}}$ as the DC bias voltage, select the sinusoidal signal of which the frequency is $600 \mathrm{kHz}$ and the duration is 5 periods as the AC input signal, and 0.01, 0.04, 0.07, $0.10 \mathrm{~V}_{\mathrm{PI}}$ as its amplitude, respectively. The waveform is 
similar to Fig. 7, but its amplitude is a little different from that.

At this time, the vibration displacement of the CMUT micro-unit is shown in Fig. 10a, and the output sound pressure is shown in Fig. 10b, and the normalized power spectrum of the output sound pressure is shown in Fig. 11. It can be seen from Fig. 10a, b that, as $\mathrm{V}_{\mathrm{AC}} \ll \mathrm{V}_{\mathrm{DC}}$, the vibration displacement of the CMUT micro-unit and the output sound pressure are related to the voltage amplitude of the AC signal at a specific DC bias voltage, and they increase with the increasing amplitude of the AC signal voltage. It can be seen from Fig. 11a, c that the change in the amplitude of the AC signal voltage has little effect on the center frequency of the output sound pressure at a specific DC bias voltage as $\mathrm{V}_{\mathrm{AC}} \ll \mathrm{V}_{\text {DC }}$. However, Fig. 11b shows that, with the increase of the amplitude of the AC signal voltage, the center frequency of the output sound pressure has a slight decreasing tendency. But, for the AC signals of different amplitudes, the center frequency of the output sound pressure is not much different from the center frequency $(600 \mathrm{kHz})$ generated by the specific DC bias voltage $0.7 \mathrm{~V}_{\mathrm{PI}}$ as a whole. In addition, it can be seen from Fig. 11c that the second harmonic signal (1.2 MHz) appearing in the output sound pressure is enhanced with the increase of the amplitude of the AC signal voltage, but it is very weak and can be neglected.

Finally, for a particular DC bias voltage, the influence of the frequency of the AC signal on the radiation characteristics of the CMUT micro-unit is analyzed as $\mathrm{V}_{\mathrm{AC}}$ $\mathrm{V}_{\mathrm{DC}}$, by selecting the AC signals of different frequencies. With $0.7 \mathrm{~V}_{\mathrm{PI}}$ as the DC bias voltage, select the sinusoidal signal of which the amplitude is $2 \mathrm{~V}$ and the duration is 5 periods as the AC input signal, and $100 \mathrm{kHz}, 300 \mathrm{kHz}$, $600 \mathrm{kHz}, 1 \mathrm{MHz}$ as its frequency, respectively. The waveform is similar to Fig. 7, but its frequency is a little different from that. The normalized power spectrum of the $\mathrm{AC}$ input signals of the four different frequencies is shown in Fig. 12.

At this time, the vibration displacement of the CMUT micro-unit is shown in Fig. 13a, the output sound pressure is shown in Fig. 13b, and the normalized power spectrum of the output sound pressure is shown in Fig. 14.

It can be seen from Fig. 13a, b that the frequency change of the AC signal will affect the vibration displacement and output sound pressure of the CMUT microunit at a specific DC bias voltage as $\mathrm{V}_{\mathrm{AC}} \ll \mathrm{V}_{\mathrm{DC}}$. For the above four AC signals of different frequencies, the $\mathrm{AC}$ signal of $600 \mathrm{kHz}$ frequency generates the maximum vibration displacement and output sound pressure, and the other three AC signals are equivalent. It is shown that only when the frequency of the AC signal is close to the center frequency generated by the specific DC bias voltage, a larger vibration displacement and output sound pressure can be obtained. It can be seen from Fig. 14a, b, the change in the frequency of the AC signal affects the frequency characteristic of the output sound pressure at a specific DC bias voltage as $\mathrm{V}_{\mathrm{AC}} \ll \mathrm{V}_{\mathrm{DC}}$. When the frequency of the AC signal is lower than the effective frequency range corresponding to the specific DC bias voltage, such as 100 and $300 \mathrm{kHz}$, the signal with the frequency similar to that of the AC signal will appear in the output sound pressure. When the frequency of the AC signal is higher than its effective frequency range, such as $1 \mathrm{MHz}$, its influence on the output sound pressure frequency will be very small. In addition, for the AC signal of different frequencies, there will be the frequency component similar to the center frequency $(600 \mathrm{kHz})$ corresponding to the specific DC bias
Fig. 10 Changes in the vibration displacement and output sound pressure with the amplitude of the AC signal changing as $\mathrm{V}_{\mathrm{AC}} \ll \mathrm{V}_{\mathrm{DC}}$. a The vibration displacement. b The output sound pressure

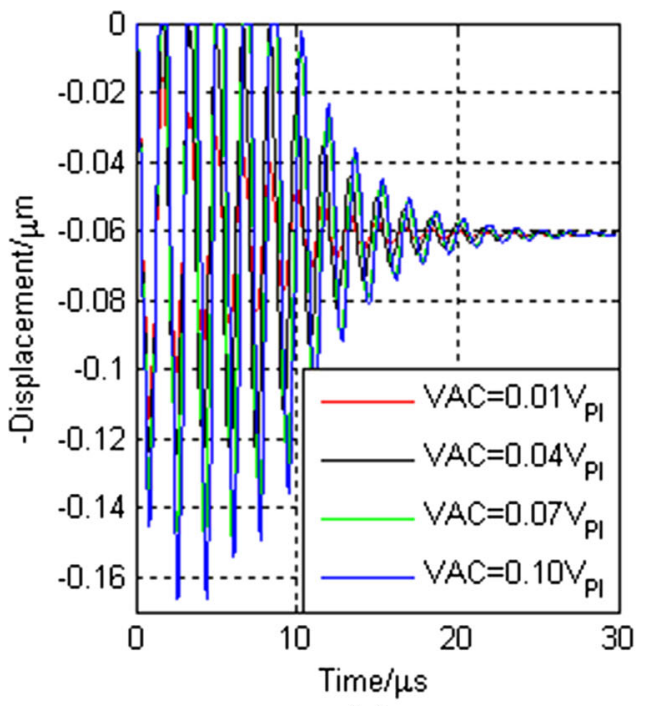

(a)

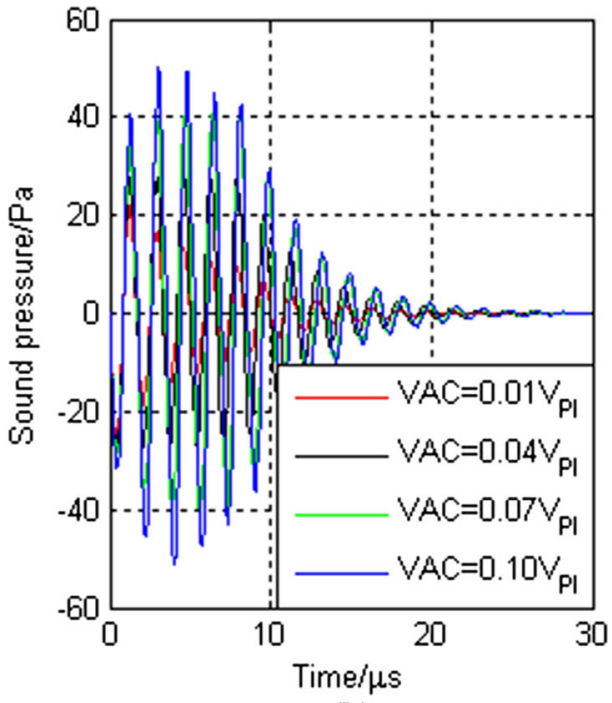

(b) 
Fig. 11 The output sound pressure power spectrum corresponding to the AC signals of different amplitudes as $\mathrm{V}_{\mathrm{AC}} \ll \mathrm{V}_{\mathrm{DC}}$. a Normalized linear power spectrum. b Normalized linear power spectrum after partial amplification. c Normalized logarithmic power spectrum

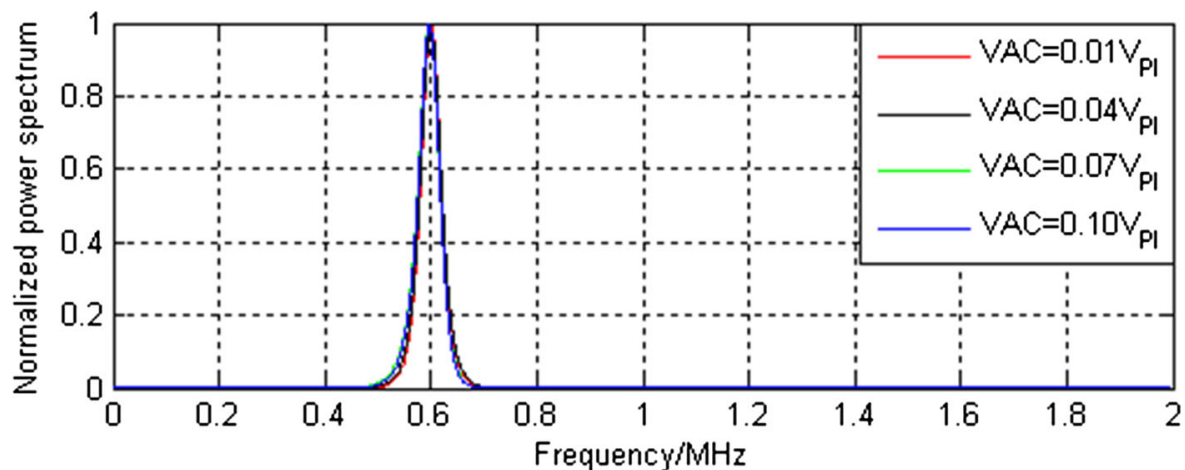

(a)

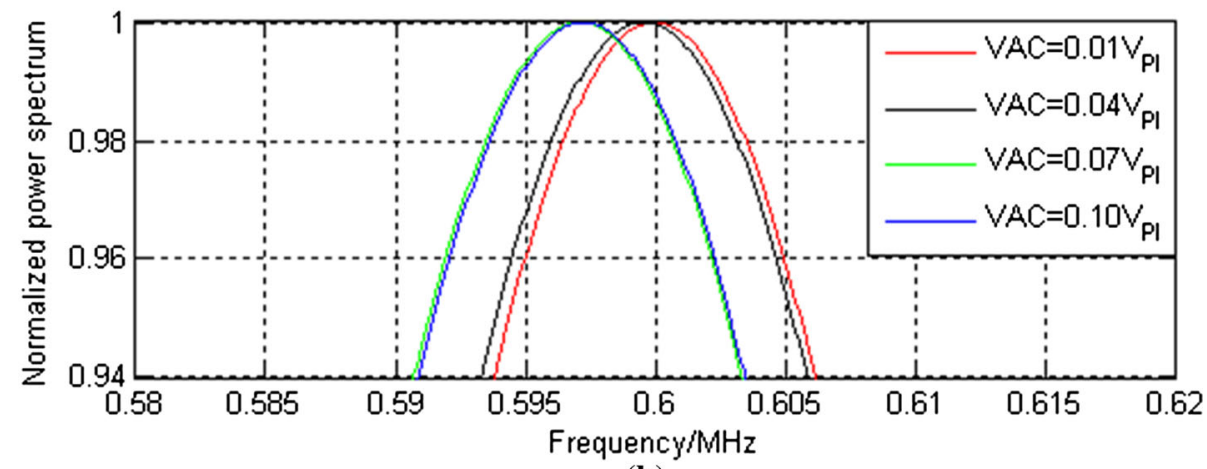

(b)

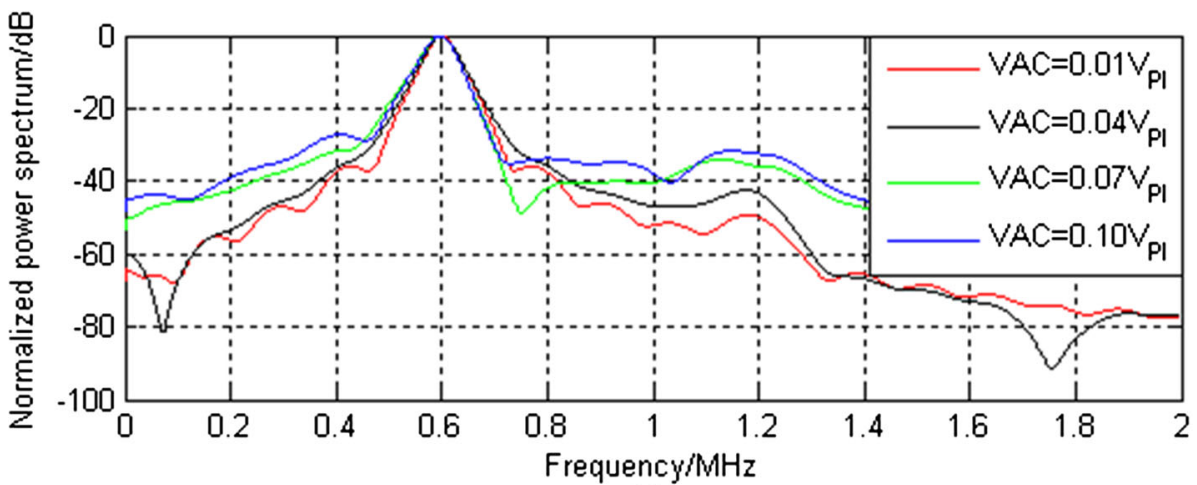

(c) voltage $0.7 \mathrm{~V}_{\mathrm{PI}}$ in the power spectrum of the output sound pressure.

\subsection{Analysis of radiation characteristics with large $\mathrm{V}_{\mathrm{AC}}$}

First, for a specific AC signal of the large amplitude, as $\mathrm{V}_{\mathrm{AC}}$ is large, the influence of the DC bias voltage on the radiation characteristics of the CMUT micro-unit is analyzed by selecting the different amplitude of the DC bias voltage. The sinusoidal signal is selected as the AC input signal, and the amplitude is $0.2 \mathrm{~V}_{\mathrm{PI}}$, the frequency is $600 \mathrm{kHz}$, the duration is 5 periods. The waveform is similar to Fig. 7, but its amplitude is a little different from that.
Respectively, select $0.2,0.4,0.7,0.9 \mathrm{~V}_{\mathrm{PI}}$ as the $\mathrm{DC}$ bias voltage.

At this time, the vibration displacement of the CMUT micro-unit is shown in Fig. 15a, and the output sound pressure is shown in Fig. 15b, and the normalized power spectrum of the output sound pressure is shown in Fig. 16. It can be seen from Fig. 15a, b that when $\mathrm{V}_{\mathrm{AC}}$ is large, the vibration displacement and output sound pressure of CMUT micro-unit increase with the increase of the DC bias voltage, and the vibration range of the film constantly expands. Figure 16a, $b$ indicate that the frequency of the output sound pressure generated by the different DC bias voltage is also different. When $\mathrm{V}_{\mathrm{AC}}$ is close to the $\mathrm{DC}$ bias voltage, there will be some lower frequency signals in the output sound pressure. But when $\mathrm{V}_{\mathrm{AC}}$ is more different 
Fig. 12 Power spectrum of the AC input signals of the four different frequencies
Fig. 13 Changes in the vibration displacement and output sound pressure with the frequency of the AC signal changing as $\mathrm{V}_{\mathrm{AC}} \ll \mathrm{V}_{\mathrm{DC}}$. a The vibration displacement. b The output sound pressure

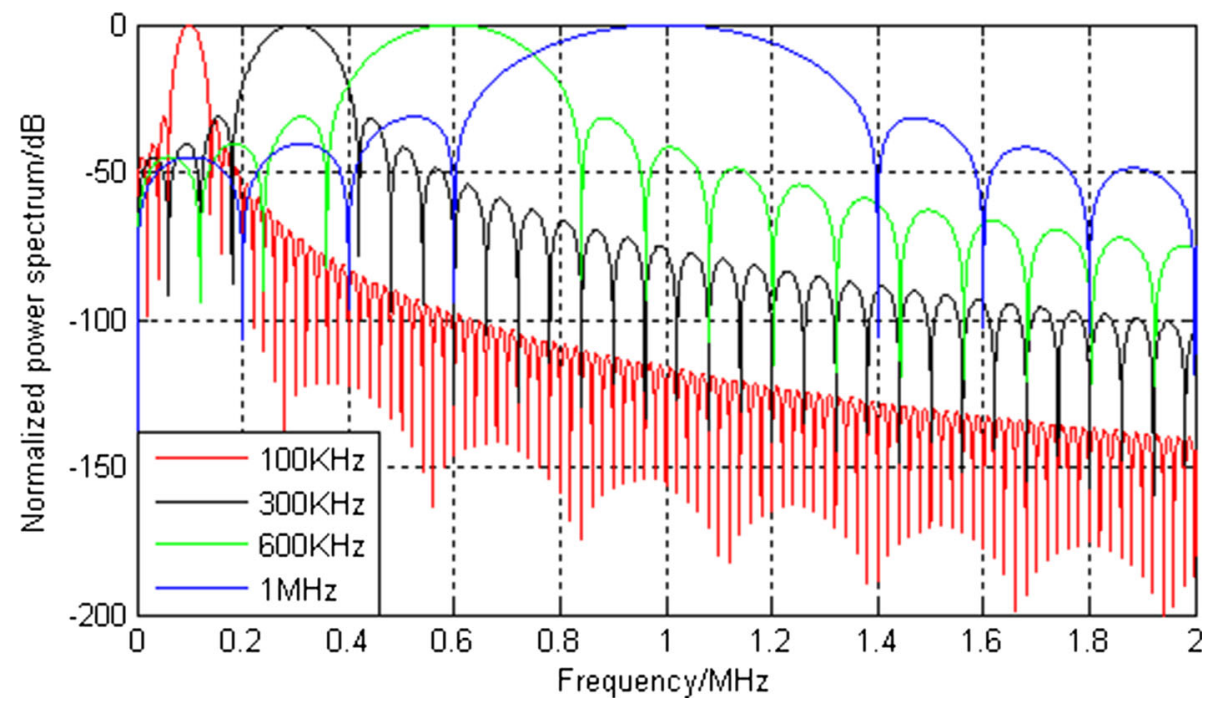

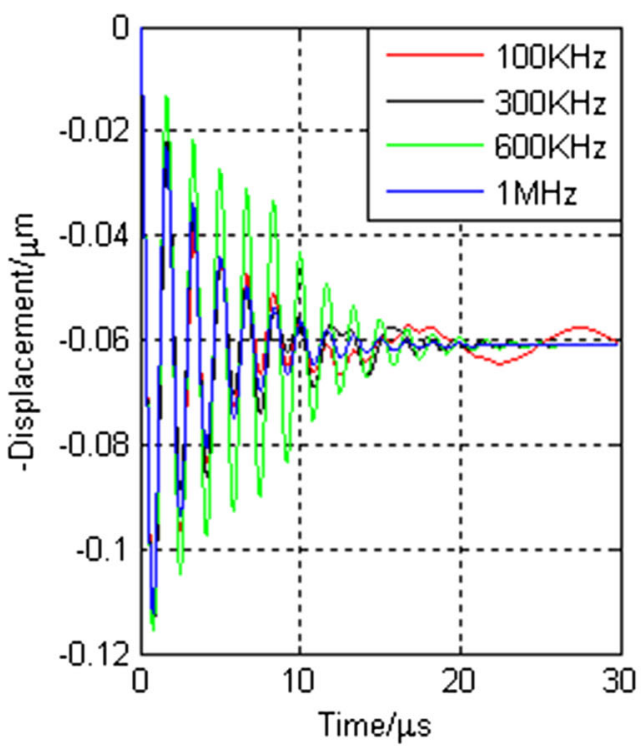

(a)

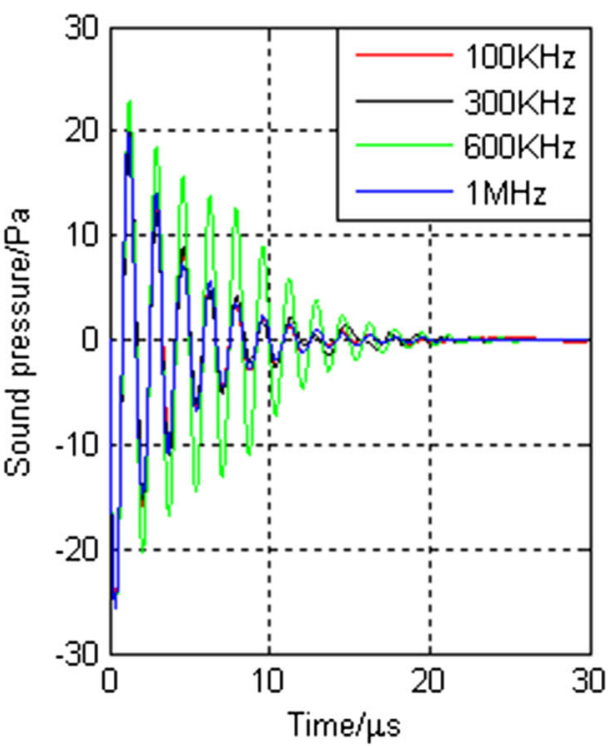

(b) from the DC bias voltage, the frequency components of output sound pressure are relatively single. The reason is mainly due to the nonlinearity of the CMUT micro-unit.

Then, for a specific DC bias voltage, as $\mathrm{V}_{\mathrm{AC}}$ is large, the influence of the amplitude of the AC signal on the radiation characteristics of the CMUT micro-unit is analyzed by selecting the AC signals of different amplitudes. With $0.6 \mathrm{~V}_{\mathrm{PI}}$ as the $\mathrm{DC}$ bias voltage, select the sinusoidal signal of which the frequency is $600 \mathrm{kHz}$ and the duration is 5 periods as the AC input signal, and $0.15,0.20,0.25$, $0.30 \mathrm{~V}_{\mathrm{PI}}$ as its amplitude, respectively. The waveform is similar to Fig. 7, but its amplitude is a little different from that.

At this time, the vibration displacement of the CMUT micro-unit is shown in Fig. 17a, and the output sound pressure is shown in Fig. 17b, and the normalized power spectrum of the output sound pressure is shown in Fig. 18.

It can be seen from Fig. 17a, $b$ that as $\mathrm{V}_{\mathrm{AC}}$ is large, the vibration displacement of the CMUT micro-unit and the output sound pressure are related to the voltage amplitude of the AC signal at a specific DC bias voltage, and they increase with the increasing amplitude of the AC signal voltage.

It can be seen from Fig. 18a-c that the change in the amplitude of the AC signal voltage will affect the center frequency of the output sound pressure at a specific DC bias voltage as $\mathrm{V}_{\mathrm{AC}}$ is large. And Fig. 18b shows that, with the increase of the amplitude of the AC signal voltage, the center frequency of the output sound pressure has a decreasing tendency. The reason is also due to the nonlinearity of the CMUT micro-unit. 
Fig. 14 The output sound pressure power spectrum corresponding to the AC signals of different frequencies as $\mathrm{V}_{\mathrm{AC}} \ll \mathrm{V}_{\mathrm{DC}}$. a Normalized linear power spectrum. b Normalized logarithmic power spectrum

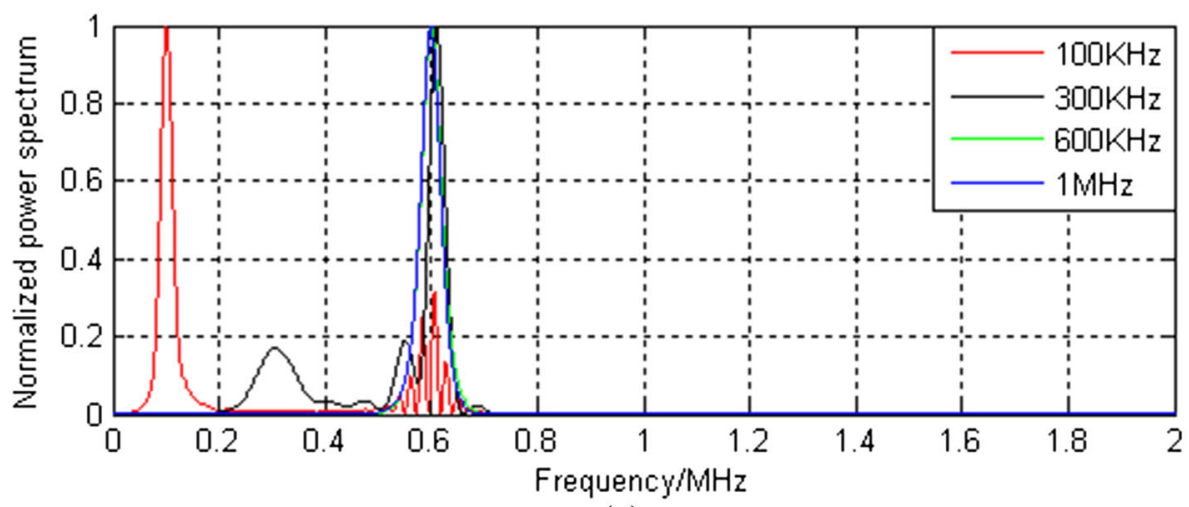

(a)

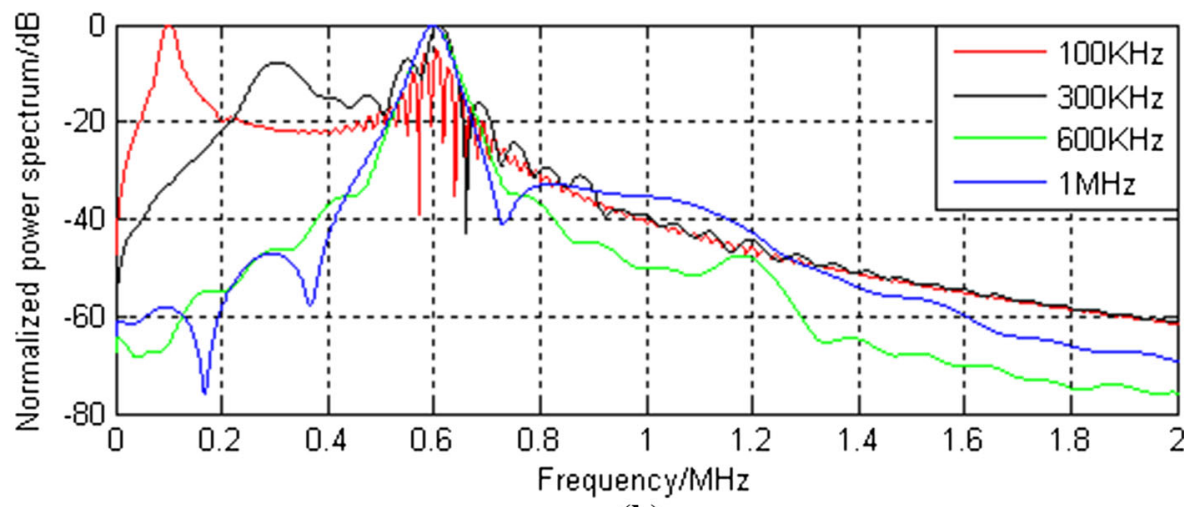

(b)

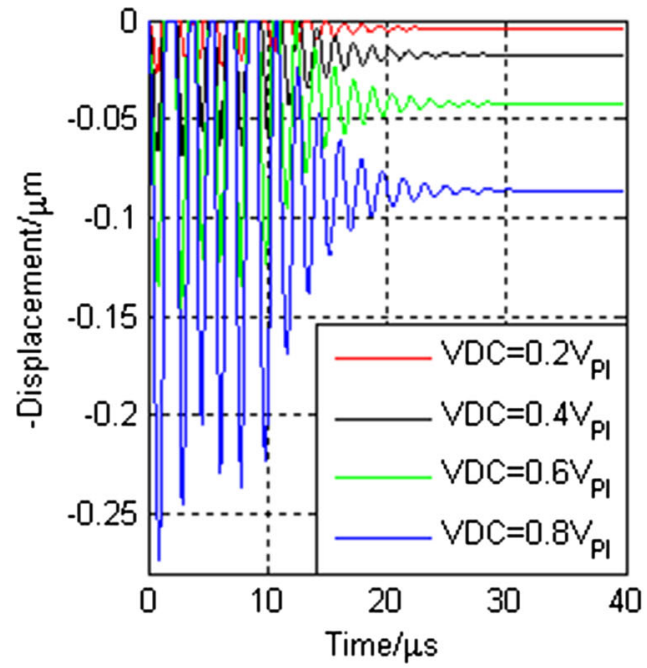

(a)

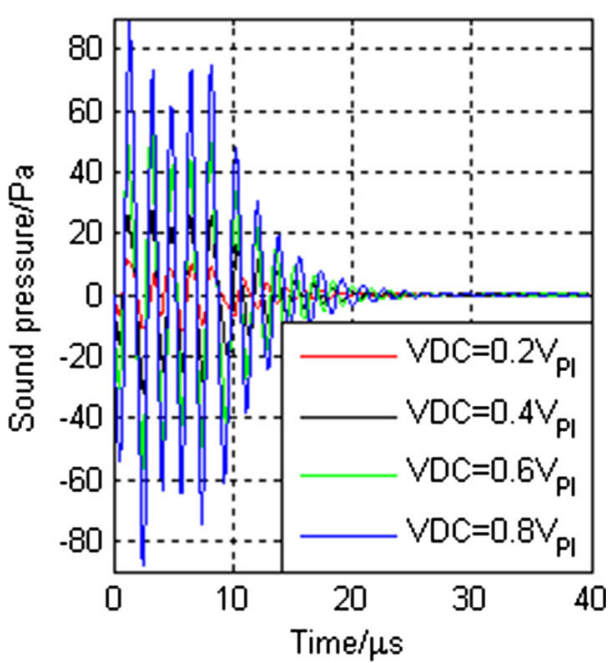

(b)
Finally, the influence of the frequency of the AC signal on the radiation characteristics of the CMUT micro-unit is analyzed as $\mathrm{V}_{\mathrm{AC}}$ is large, by selecting the $\mathrm{AC}$ signals of different frequencies. With $\mathrm{V}_{\mathrm{DC}}=0.6 \mathrm{~V}_{\mathrm{PI}}, \mathrm{V}_{\mathrm{AC}}=0.2 \mathrm{~V}_{\mathrm{PI}}$, select the sinusoidal signal of which the amplitude is $2 \mathrm{~V}$ and the duration is 5 periods as the $\mathrm{AC}$ input signal, and $100 \mathrm{kHz}, 300 \mathrm{kHz}, 600 \mathrm{kHz}, 1 \mathrm{MHz}$ as its frequency, respectively. The waveform is similar to Fig. 7, but its amplitude and frequency are a little different from that. The normalized power spectrum is similar to Fig. 12.

At this time, the vibration displacement of the CMUT micro-unit is shown in Fig. 19a, the output sound pressure is shown in Fig. 19b, and the normalized power spectrum of the output sound pressure is shown in Fig. 20.

It can be seen from Fig. 19a, b that the change in the frequency of the AC signal will affect the vibration 
Fig. 16 The output sound pressure power spectrum corresponding to different DC bias voltages as $\mathrm{V}_{\mathrm{AC}}$ is large. a Normalized linear power spectrum. b Normalized logarithmic power spectrum

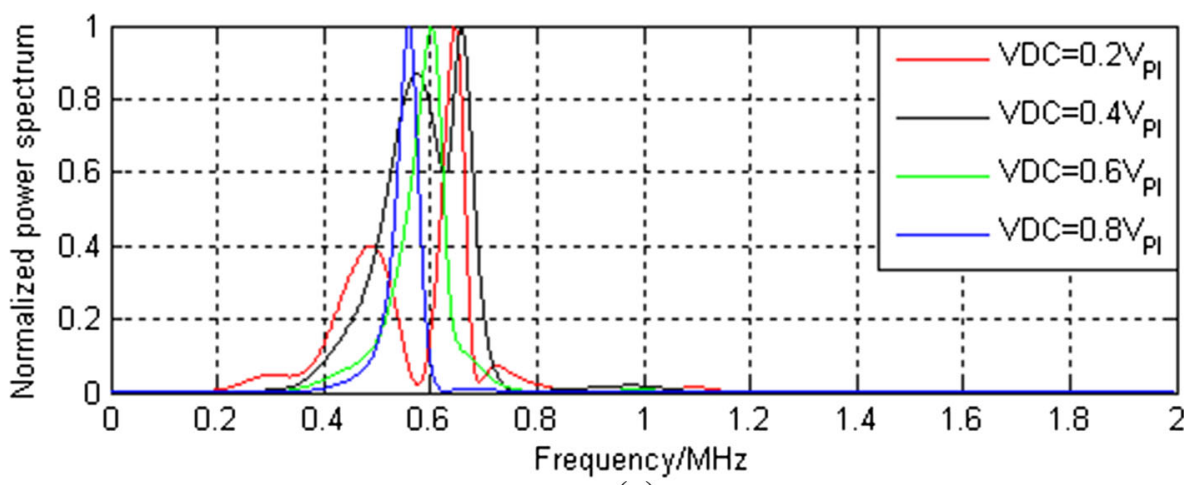

(a)

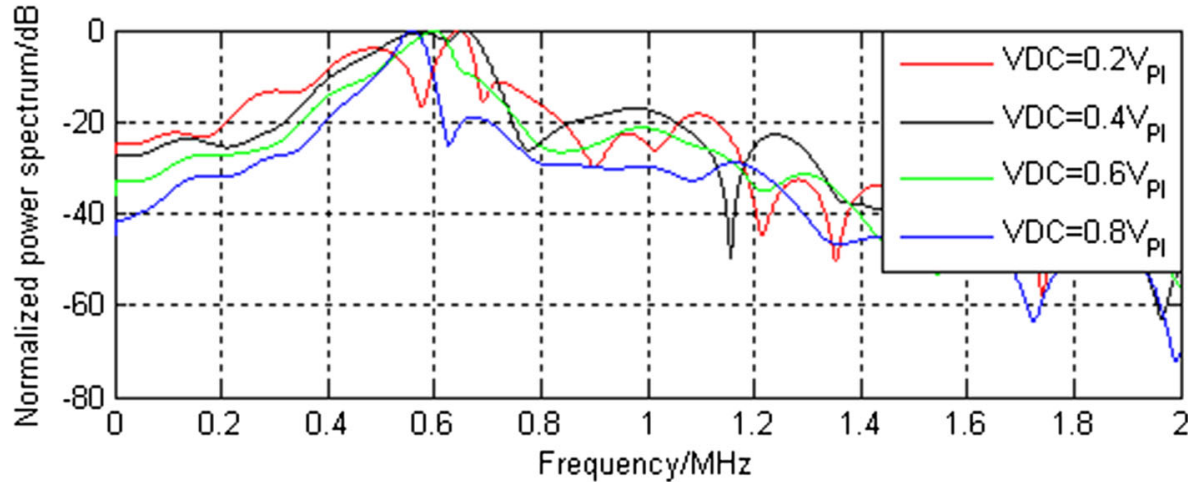

(b)
Fig. 17 Changes in the vibration displacement and output sound pressure with the amplitude of the AC signal changing as $\mathrm{V}_{\mathrm{AC}}$ is large. a The vibration displacement. b The output sound pressure

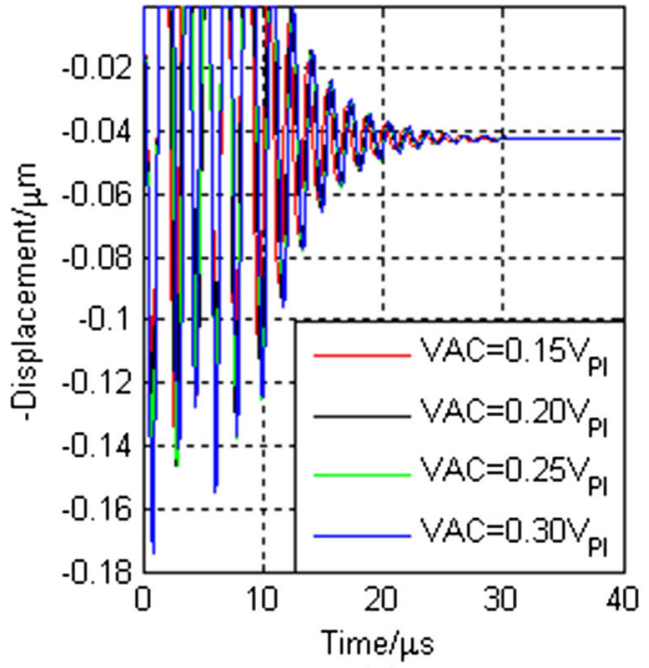

(a)

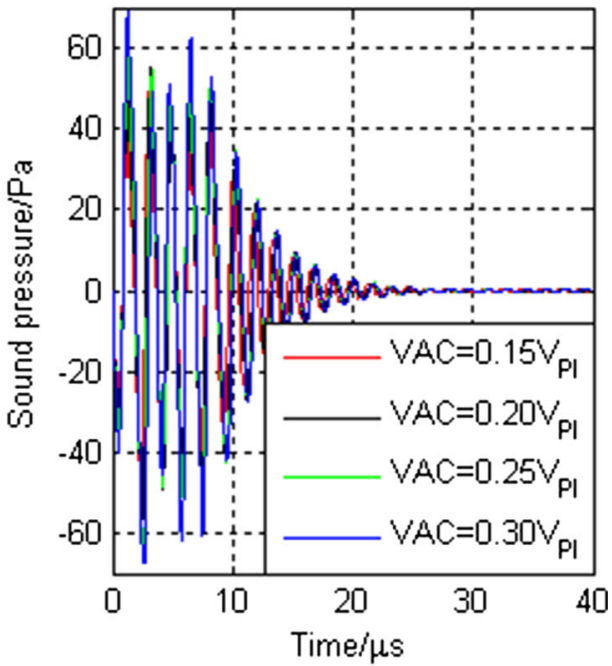

(b) displacement and output sound pressure of the CMUT micro-unit as $\mathrm{V}_{\mathrm{AC}}$ is large. For the above four $\mathrm{AC}$ signals of different frequencies, the AC signal of $600 \mathrm{kHz}$ frequency generates the maximum vibration displacement and output sound pressure, the second is the AC signal of $300 \mathrm{kHz}$ frequency, the third is the $\mathrm{AC}$ signal of $1 \mathrm{MHz}$ frequency and the final is the AC signal of $100 \mathrm{kHz}$ frequency. This is mainly due to the fact that the frequency $600 \mathrm{kHz}$ is close to the center frequency corresponding to the DC bias voltage $\mathrm{V}_{\mathrm{DC}}=0.6 \mathrm{~V}_{\mathrm{PI}}$, which make it generate the maximum vibration displacement and output sound pressure. For the AC signal with a frequency of $300 \mathrm{kHz}$, the second harmonic signal $(600 \mathrm{kHz})$ in $\mathrm{V}^{2}$ is evident clearly because of the large $\mathrm{V}_{\mathrm{AC}}$, and the frequency of the second harmonic is also close to the center frequency corresponding to the $\mathrm{DC}$ bias voltage $\mathrm{V}_{\mathrm{DC}}=0.6 \mathrm{~V}_{\mathrm{PI}}$. Therefore, the vibration signal and the output sound pressure generated by the AC signal with the frequency of 
Fig. 18 The output sound pressure power spectrum corresponding to the AC signals of different amplitudes as $\mathrm{V}_{\mathrm{AC}}$ is large. a Normalized linear power spectrum. b Normalized linear power spectrum after partial amplification.

c Normalized logarithmic power spectrum

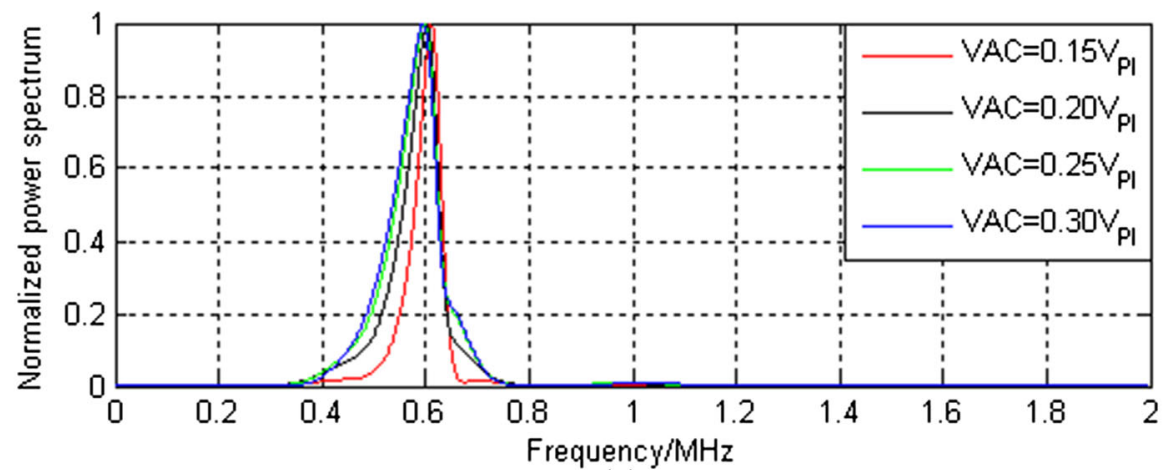

(a)

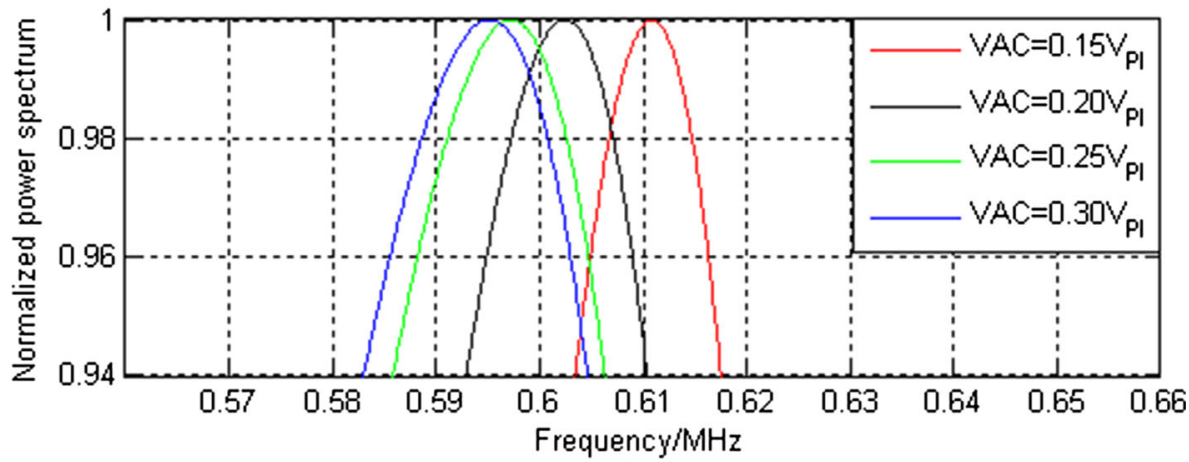

(b)

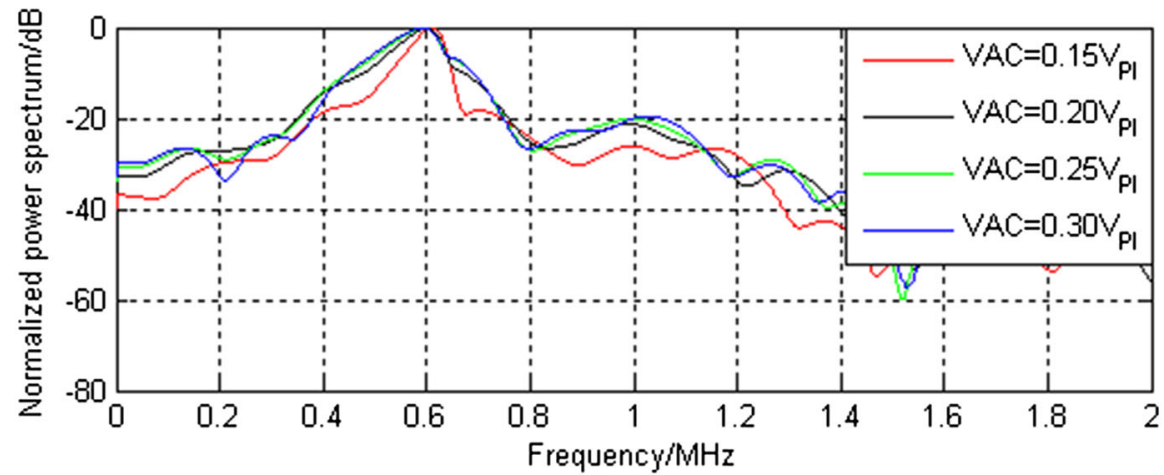

(c)
$300 \mathrm{kHz}$ are larger than that of the $\mathrm{AC}$ signal at $100 \mathrm{kHz}$ and $1 \mathrm{MHz}$.

It can be seen from Fig. 20a, b, as $\mathrm{V}_{\mathrm{AC}}$ is large, the frequency change of the $\mathrm{AC}$ signal has a effect on the output sound pressure which is similar to that as $\mathrm{V}_{\mathrm{AC}}$ $\mathrm{V}_{\mathrm{DC}}$. When the frequency of the AC signal is lower than the effective frequency range corresponding to the specific DC bias voltage, such as $100,300 \mathrm{kHz}$, the signal with the frequency similar to that of the AC signal will appear in the output sound pressure. When the frequency of the AC signal is higher than its effective frequency range, such as $1 \mathrm{MHz}$, its influence on the output sound pressure frequency will be very small. In addition, for the AC signal of different frequencies, there will be the frequency component similar to the center frequency corresponding to the specific DC bias voltage in the power spectrum of the output sound pressure.

\subsection{Analysis of radiation characteristics as $\mathrm{V}_{\mathrm{DC}}=0$}

When $\mathrm{V}_{\mathrm{DC}}=0$, Formula (7) can be obtained based on Formula (6). Formula (7) shows that as $\mathrm{V}_{\mathrm{DC}}=0$, if the $\mathrm{AC}$ signal with the frequency of $f_{s} / 2$ is directly selected as the input voltage, then that can make the input voltage of the square $\mathrm{V}^{2}$ only contains the signal with the frequency of $\mathrm{f}_{\mathrm{s}}$. Thus, it is assumed that the desired output voltage with the frequency of $\mathrm{f}_{\mathrm{s}}$ can be obtained. 
Fig. 19 Changes in the vibration displacement and output sound pressure with the frequency of the AC signal changing as $\mathrm{V}_{\mathrm{AC}}$ is large. a The vibration displacement. b The output sound pressure

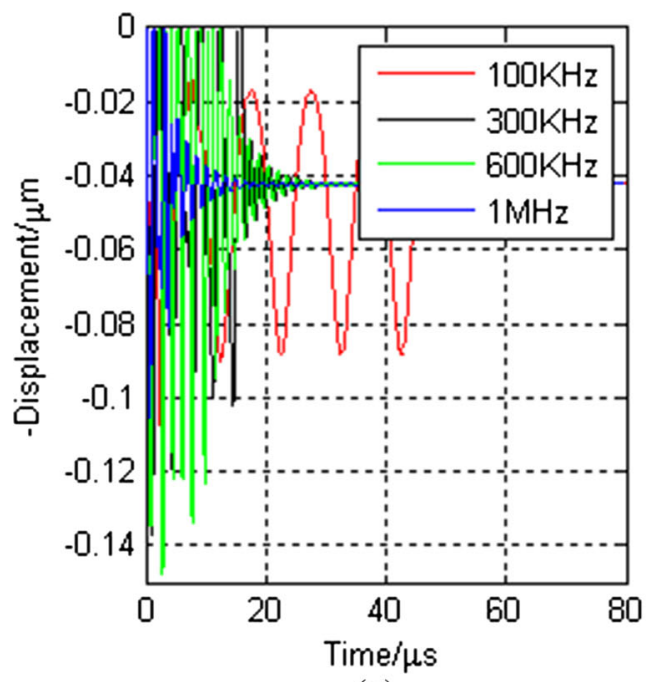

(a)

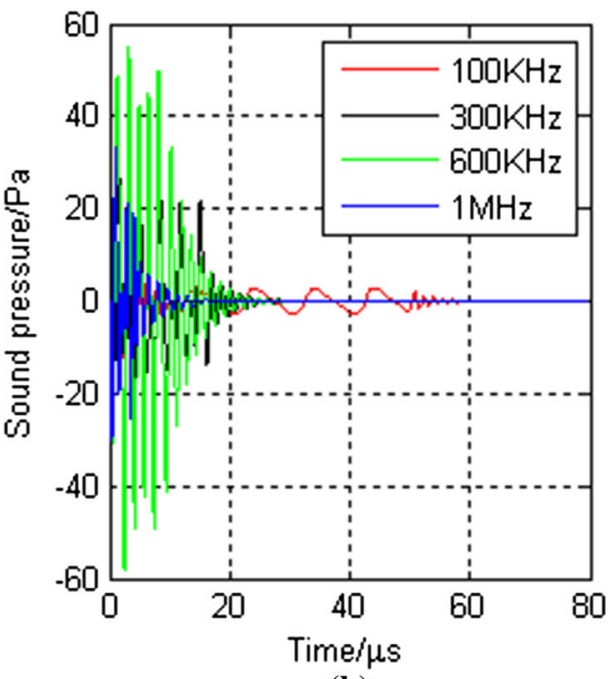

(b)
Fig. 20 The output sound pressure power spectrum corresponding to the $\mathrm{AC}$ signals of different frequencies as $\mathrm{V}_{\mathrm{AC}}$ is large. a Normalized linear power spectrum. b Normalized logarithmic power spectrum

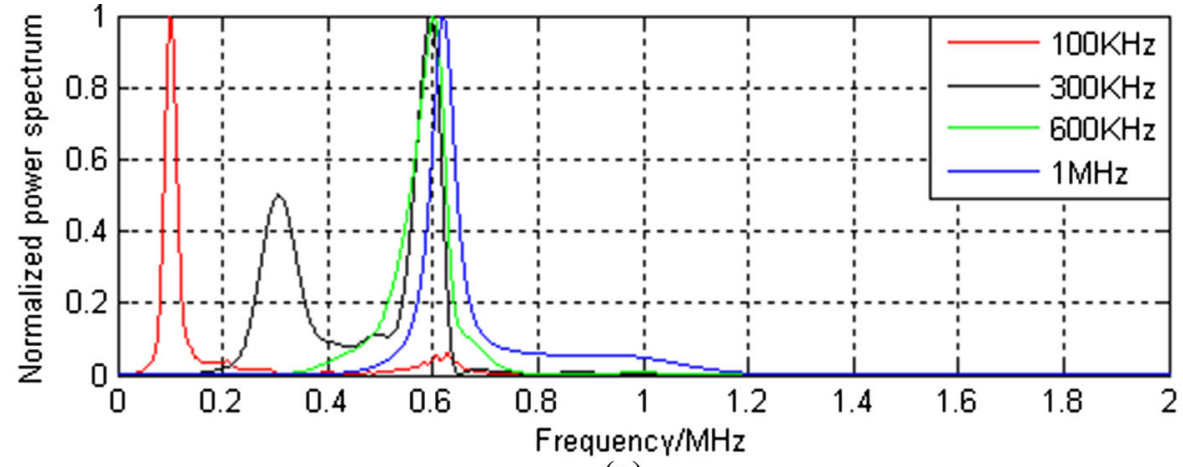

(a)

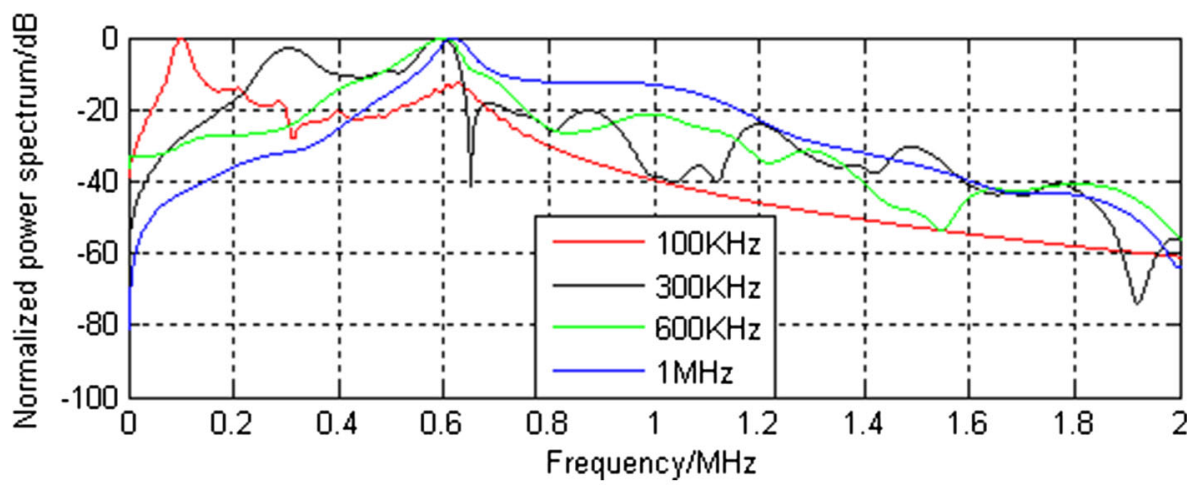

(b)

$$
\begin{aligned}
V^{2} & =\frac{1}{2} V_{A C}^{2}-\frac{1}{2} V_{A C}^{2} \cos \left(4 \pi f_{s} t\right) \\
& =\frac{1}{2} V_{A C}^{2}-\frac{1}{2} V_{A C}^{2} \cos \left(2 \pi f_{s}^{\prime} t\right) .
\end{aligned}
$$

In order to obtain the output sound pressure with the frequency of $600 \mathrm{kHz}$, select the sinusoidal signal of which the frequency is $300 \mathrm{kHz}$ and the duration is 5 periods as the $\mathrm{AC}$ input signal, and $0.2,0.4,0.6,0.8 \mathrm{~V}_{\mathrm{PI}}$ as its amplitude, respectively. The waveform is similar to Fig. 7, but its amplitude and frequency is a little different from that.

At this time, the vibration displacement of the CMUT micro-unit is shown in Fig. 21a, and the output sound pressure is shown in Fig. 21b, and the normalized power spectrum of the output sound pressure is shown in Fig. 22.

It can be seen from Fig. $21 \mathrm{a}$, b that as $\mathrm{V}_{\mathrm{DC}}=0$, the vibration displacement and the output sound pressure of the CMUT micro-unit are related to the voltage amplitude of 
Fig. 21 Changes in the vibration displacement and output sound pressure with the amplitude of the AC signal changing as $\mathrm{V}_{\mathrm{DC}}=0$. a The vibration displacement. b The output sound pressure

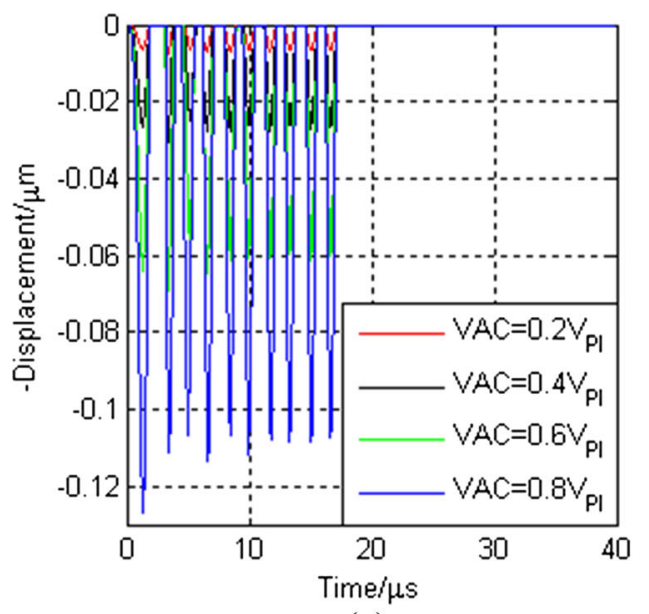

(a)

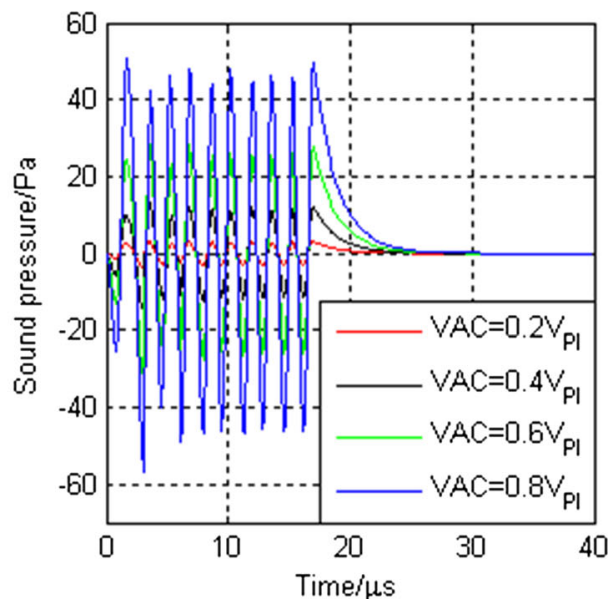

(b)
Fig. 22 The output sound pressure power spectrum corresponding to the AC signals of different amplitudes as $\mathrm{V}_{\mathrm{DC}}=0$. a Normalized linear power spectrum. b Normalized logarithmic power spectrum

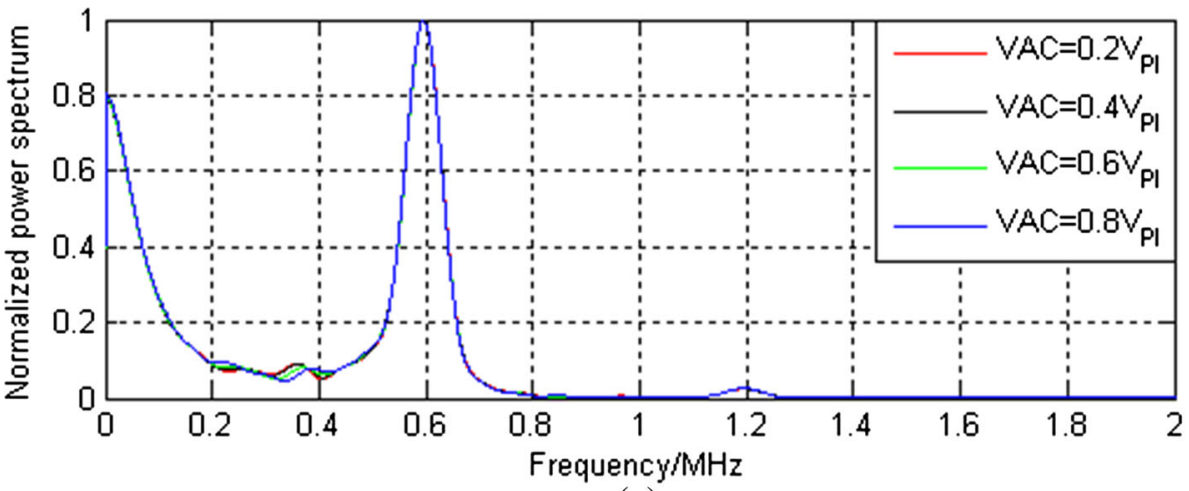

(a)

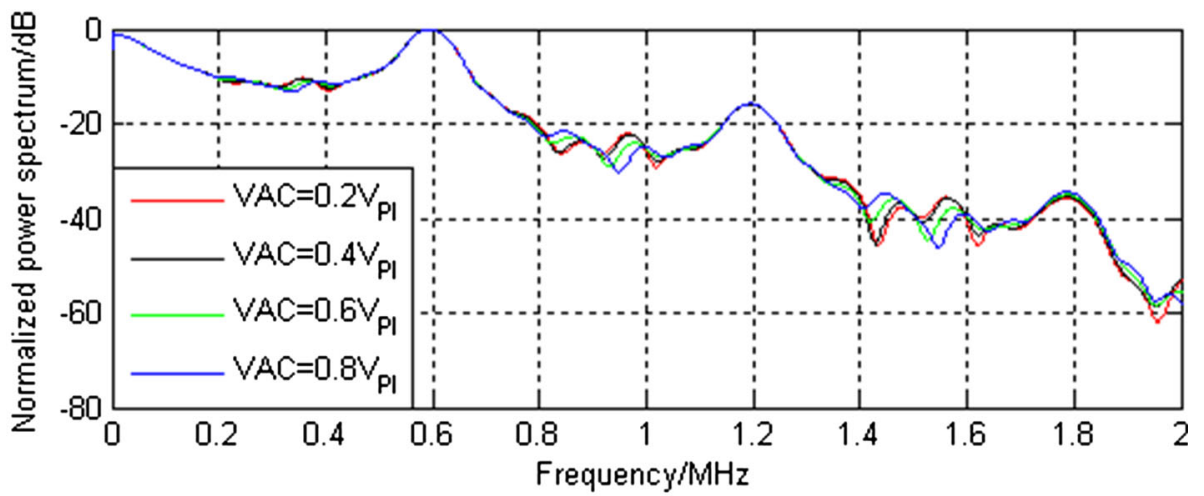

(b) the AC signal at a specific DC bias voltage, and they increase with the increasing amplitude of the AC signal voltage.

Figure $22 \mathrm{a}$, b show that, as $\mathrm{V}_{\mathrm{DC}}=0$, the $\mathrm{AC}$ signal with frequency $f_{s} / 2$ is directly used as the input voltage, and the generated output sound pressure contains the signal with frequency $f_{s}$. Also, it contains the harmonic signals of other different orders of the AC signal. The reason for this is that the nonlinearity of the CMUT is more strongly affected by the dynamic space $g$ than $V^{2}$. Therefore, it is actually invalid to eliminate the harmonic effect by using the Formula (7) simply. To reduce the influence of the nonlinear harmonic in the output sound pressure of the CMUT on the image quality, the filtering, signal compensation and other methods can be used to achieve it (Novell et al. 2009). 


\subsection{Analysis of the influence of the period number of $A C$ signal on radiation characteristics}

It is in the above analyses that the AC input signal with the duration of 5 periods are used. And there will be a analysis of the influence of the period number of the $\mathrm{AC}$ input signal on the radiation characteristics of the CMUT for the $\mathrm{AC}$ input signals of different period number.

First, the influence of the period number of the AC input signal on the radiation characteristics of the CMUT is analyzed as $\mathrm{V}_{\mathrm{AC}} \ll \mathrm{V}_{\mathrm{DC}}$. In addition, with $0.7 \mathrm{~V}_{\mathrm{PI}}$ as the DC bias voltage, the sinusoidal signal of which the amplitude is $2 \mathrm{~V}$ and the frequency is $600 \mathrm{kHz}$ is selected as the AC input signal, and the duration of it is 1 period, 5 periods, 10 periods and 20 periods, respectively. Its time domain waveform and normalized power spectrum are shown in Fig. 23a, b, respectively. It can be seen from the power spectrum shown in Fig. 23b that the effective bandwidth of the AC input signal becomes narrower as the period number increases.

At this time, the vibration displacement of the CMUT micro-unit is shown in Fig. 24a, and the output sound pressure is shown in Fig. 24b, and the normalized power spectrum of the output sound pressure is shown in Fig. 25.

It can be seen from Fig. 24a, b that as $\mathrm{V}_{\mathrm{AC}} \ll \mathrm{V}_{\mathrm{DC}}$, the period number of the AC input signal mainly affects the vibration displacement and the output sound pressure of the
CMUT micro-unit duration and attenuation rate. With the increase of the period number, the duration of the vibration displacement and the output sound pressure becomes longer and the attenuation becomes slower. In addition, the longer the duration of the AC input signal is, the larger the amplitude of the output sound pressure and the vibration displacement of the CMUT micro-unit will become.

It can be seen from Fig. 25a, b that as $\mathrm{V}_{\mathrm{AC}} \ll \mathrm{V}_{\mathrm{DC}}$, the period number of the AC input signal mainly affects the effective bandwidth of the output sound pressure, and the effective bandwidth of the output sound pressure gradually becomes narrower as the period number increases.

Then, the influence of the period number of the AC input signal on the radiation characteristics of the CMUT is analyzed as $\mathrm{V}_{\mathrm{AC}}$ is large. In addition, with $0.6 \mathrm{~V}_{\mathrm{PI}}$ as the DC bias voltage, the sinusoidal signal of which the amplitude is $2 \mathrm{~V}$ and the frequency is $600 \mathrm{kHz}$ is selected as the AC input signal, and the duration of it is 1 period, 5 periods, 10 periods and 20 periods, respectively. The waveform is similar to Fig. 23, but its amplitude is a little different from that.

At this time, the vibration displacement of the CMUT micro-unit is shown in Fig. 26a, and the output sound pressure is shown in Fig. 26b, and the normalized power spectrum of the output sound pressure is shown in Fig. 27.

It can be seen from Fig. 26a, $b$ that as $\mathrm{V}_{\mathrm{AC}}$ is large, the influence of the period number of the AC input signal is similar to that when $\mathrm{V}_{\mathrm{AC}} \ll \mathrm{V}_{\mathrm{DC}}$. With the increase of the
Fig. 23 The AC signals with different period number. a The time domain waveform of the AC signal. b The power spectrum of the AC signal

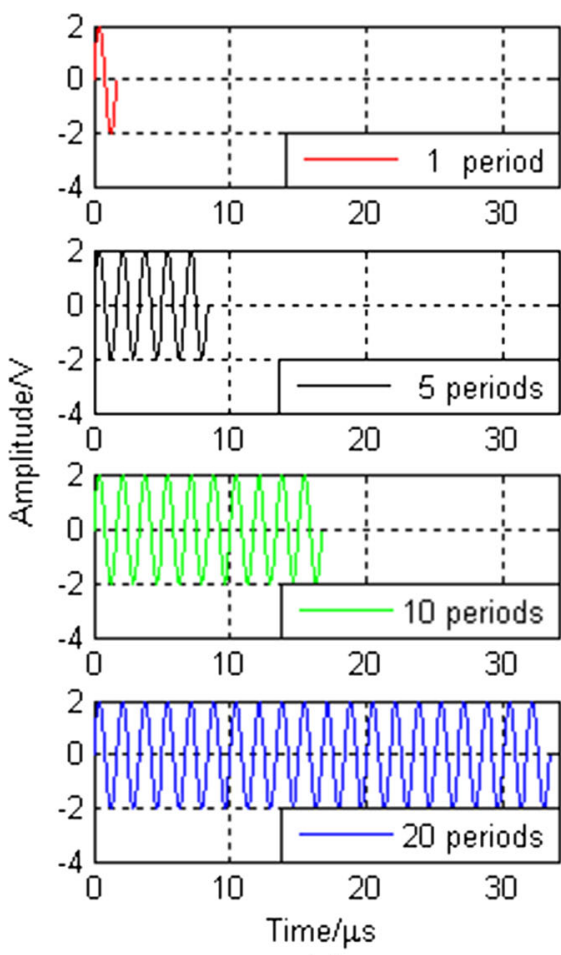

(a)

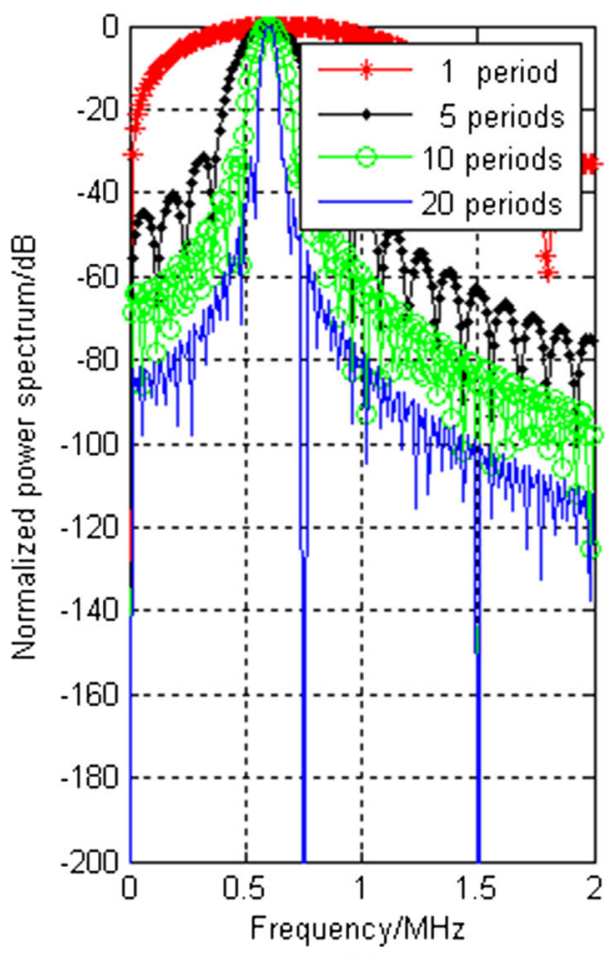

(b) 
Fig. 24 Changes in the vibration displacement and output sound pressure with the period number of the AC signal changing as $\mathrm{V}_{\mathrm{AC}} \ll \mathrm{V}_{\mathrm{DC}}$. a The vibration displacement. b The output sound pressure

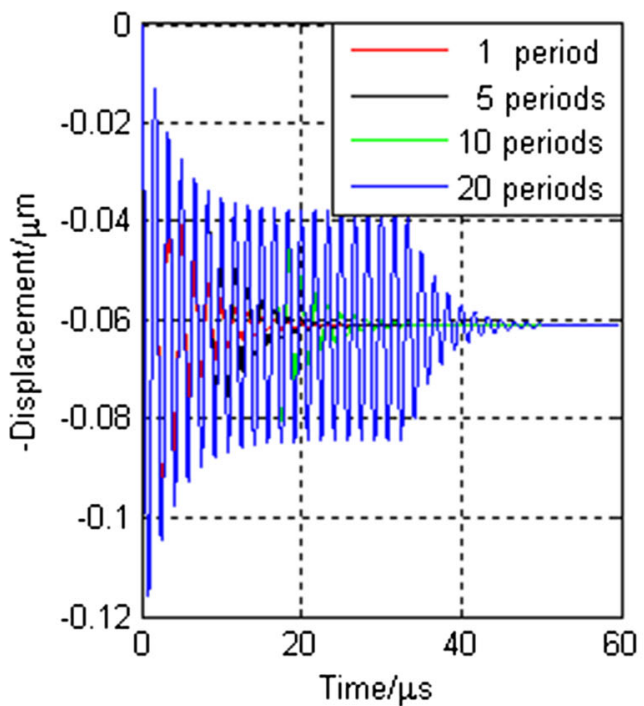

(a)

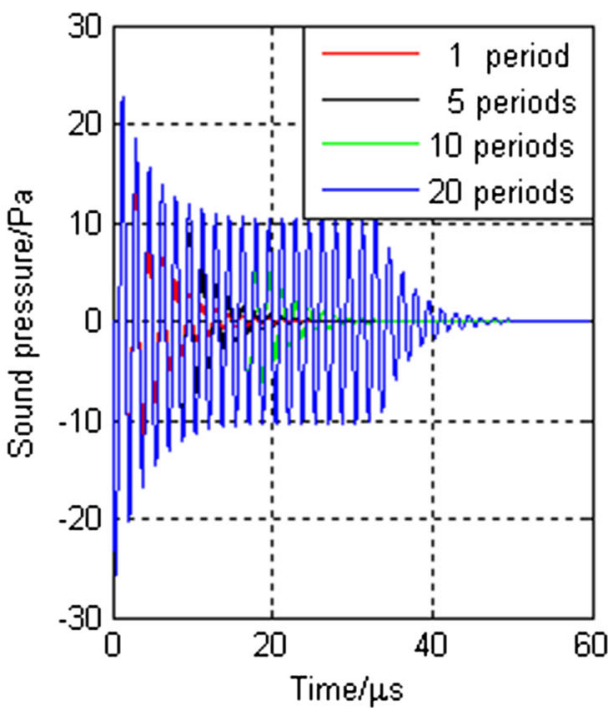

(b)

Fig. 25 The output sound pressure power spectrum corresponding to the $\mathrm{AC}$ signals of different period number as $\mathrm{V}_{\mathrm{AC}} \ll \mathrm{V}_{\mathrm{DC}}$. a Normalized linear power spectrum. b Normalized logarithmic power spectrum

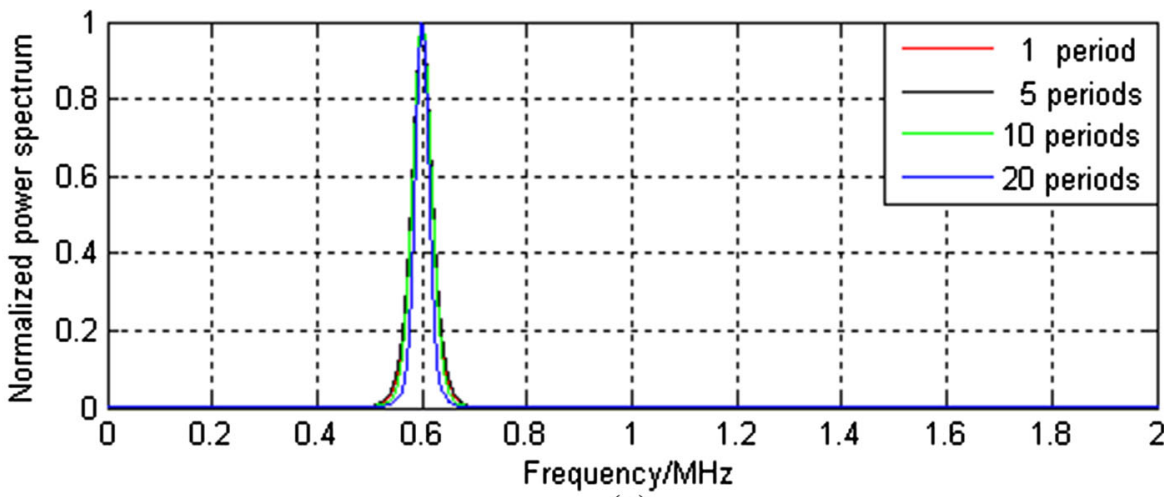

(a)

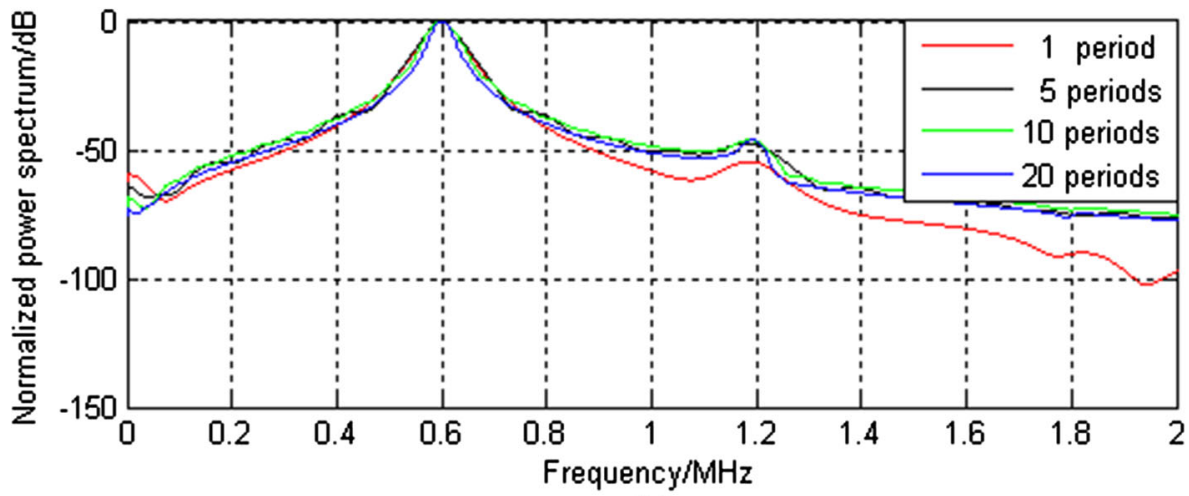

(b)

period number, the duration of the vibration displacement and the output sound pressure becomes longer and the attenuation becomes slower.

It can be seen from Fig. 27a, b, as $\mathrm{V}_{\mathrm{AC}}$ is large, the center frequency of the output sound pressure tends to decrease gradually with the increase of the period number of the AC input signal, and its effective bandwidth gradually becomes narrow, but its second harmonic signal becomes more and more evident.

Finally, the influence of the period number of the AC input signal on the radiation characteristics of the CMUT is analyzed as $\mathrm{V}_{\mathrm{DC}}=0$. Here, the sinusoidal signal of which the amplitude is $0.8 \mathrm{~V}_{\mathrm{PI}}$ and the frequency The frequency is $300 \mathrm{kHz}$ which is half of the desired frequency, and the duration of it is 1 period, 5 periods, 10 periods, 20 periods, 
Fig. 26 Changes in the vibration displacement and output sound pressure with the period number of the AC signal changing as $\mathrm{V}_{\mathrm{AC}}$ is large. a The vibration displacement. b The output sound pressure

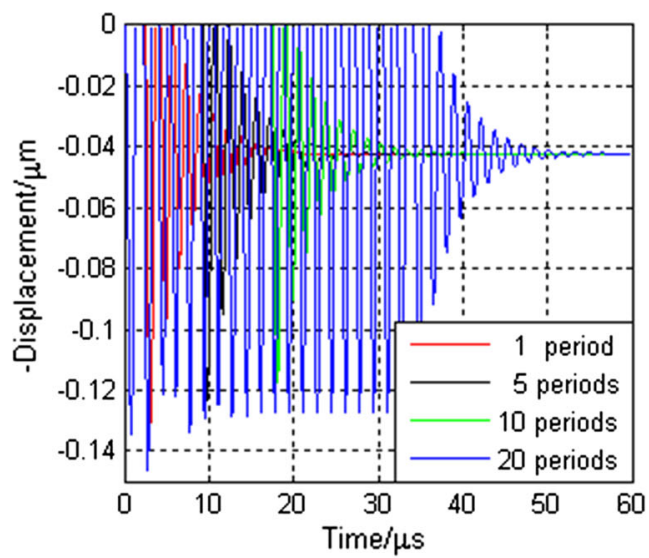

(a)

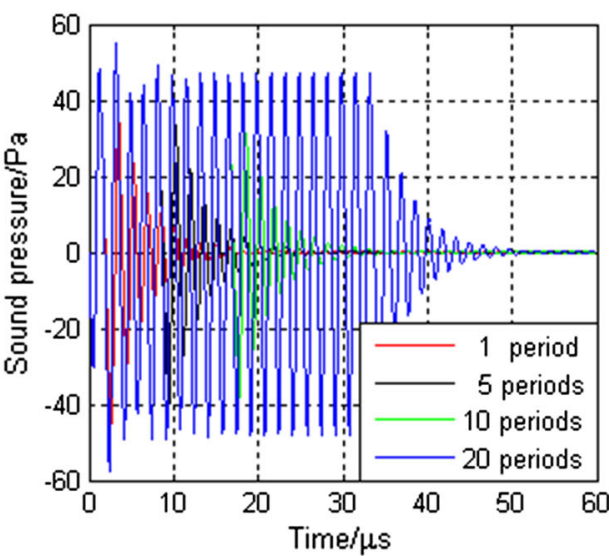

(b)

Fig. 27 The output sound pressure power spectrum corresponding to the $\mathrm{AC}$ signals of different period number as $\mathrm{V}_{\mathrm{AC}}$ is large. a Normalized linear power spectrum. b Normalized logarithmic power spectrum

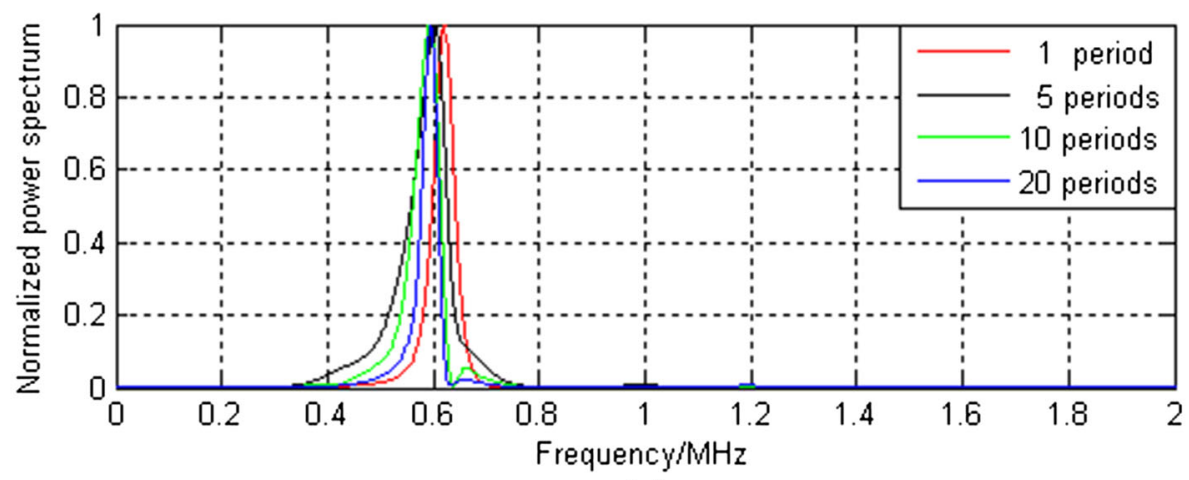

(a)

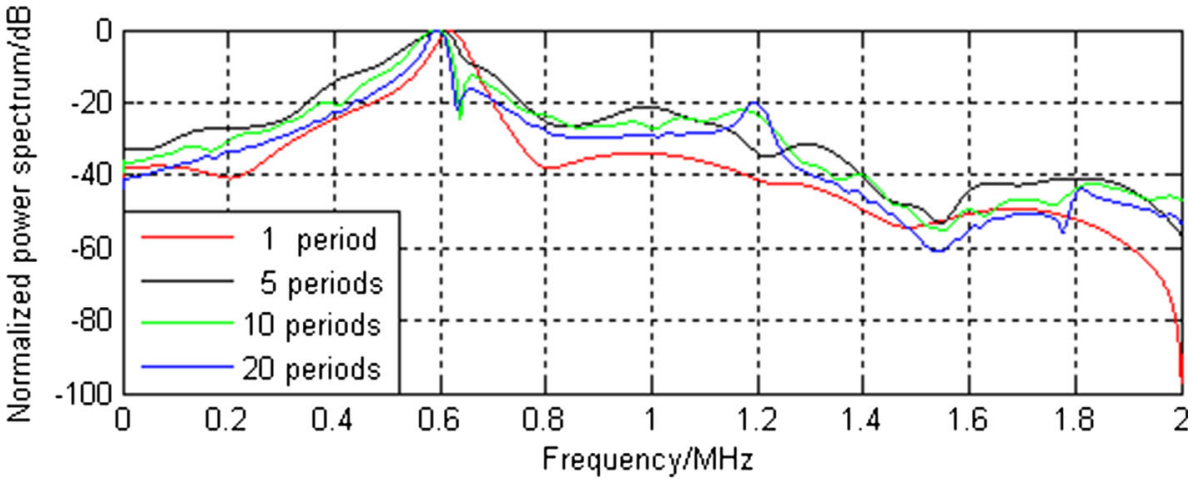

(b)

respectively. The waveform is similar to Fig. 23, but its amplitude and frequency are a little different from that.

At this time, the vibration displacement of the CMUT micro-unit is shown in Fig. 28a, and the output sound pressure is shown in Fig. 28b, and the normalized power spectrum of the output sound pressure is shown in Fig. 29.

It can be seen from Fig. 28a, b that as $\mathrm{V}_{\mathrm{DC}}=0$, the influence of the period number of the AC input signal is similar to that when $\mathrm{V}_{\mathrm{AC}} \ll \mathrm{V}_{\mathrm{DC}}$ and $\mathrm{V}_{\mathrm{AC}}$ is large. With the increase of the period number, the duration of the vibration displacement and the output sound pressure becomes longer and the attenuation becomes slower.
It can be seen from Fig. 29a, b, as $\mathrm{V}_{\mathrm{DC}}=0$, with the period number of the AC input signal increases, the desired vibration frequency $(600 \mathrm{kHz})$ is gradually increased and the effective bandwidth of the output sound pressure becomes narrower. However, the second and third harmonic signals of the desired frequency also become more and more evident. In addition, it can be clearly seen that for an AC input signal with the duration of one period, the bandwidth of the corresponding radiation sound pressure is very wide and the desired frequency component cannot be distinguished. This is mainly due to the fact that the duration of the output sound pressure is too short. 
Fig. 28 Changes in the vibration displacement and output sound pressure with the period number of the AC signal changing as $\mathrm{V}_{\mathrm{DC}}=0$. a The vibration displacement. b The output sound pressure

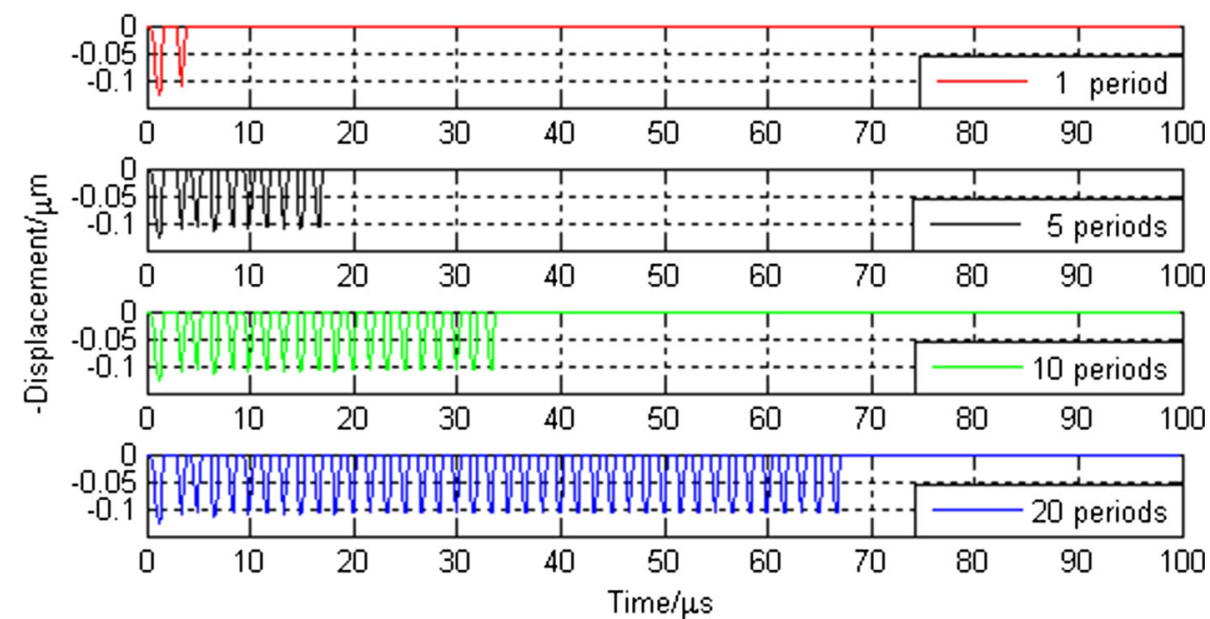

(a)

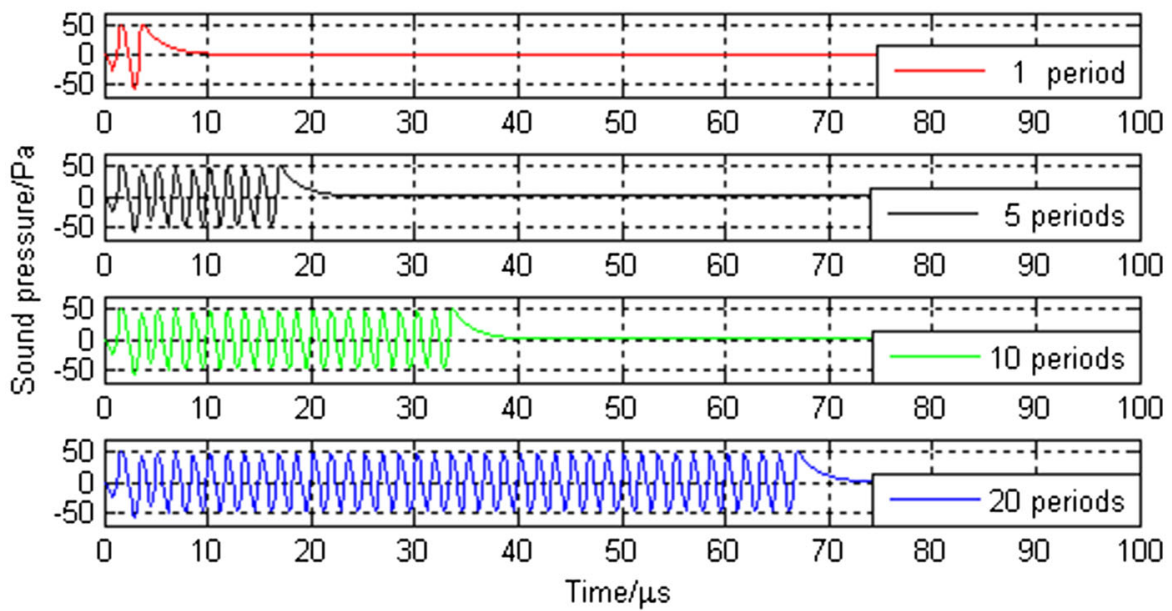

(b)
Therefore, as $\mathrm{V}_{\mathrm{DC}}=0$, it is not appropriate to select an $\mathrm{AC}$ input signal with a duration of one period.

\section{Conclusions}

Based on the lumped parameter system model of the CMUT micro-unit, the state equation in the radiation state is deduced in this paper, and there is the modeling analysis through SIMULINK. With the analysis of the influence of different input signals on its radiation characteristics, the following conclusions can be drawn:

1. As $\mathrm{V}_{\mathrm{AC}}$ is small, the $\mathrm{DC}$ bias voltage, the amplitude and frequency of the AC signal will affect the vibration displacement and output sound pressure of the CMUT micro-unit. The frequency characteristics of the output sound pressure of the CMUT micro-unit are greatly influenced by the DC bias voltage, and less affected by the amplitude of the AC signal. But, the frequency change of the AC signal will also affect the frequency characteristics of the output sound pressure of the CMUT micro-unit. In practical applications, in order to obtain a large output sound pressure, the frequency of the AC signal should be close to the center frequency corresponding to the specific DC bias voltage and the amplitude should be increased as much as possible.

2. As $\mathrm{V}_{\mathrm{AC}}$ is large, the $\mathrm{DC}$ bias voltage, the amplitude and frequency of the AC signal will affect the vibration displacement and output sound pressure of the CMUT micro-unit. The frequency characteristics of the output sound pressure of the CMUT micro-unit are greatly influenced by the DC bias voltage, and less affected by the amplitude of the AC signal. In this case, the influence on the radiation characteristics is similar to that when $\mathrm{V}_{\mathrm{AC}}$ is small, and there is little difference between them.

3. As $\mathrm{V}_{\mathrm{DC}}=0$, the $\mathrm{AC}$ signal with frequency $\mathrm{f}_{\mathrm{s}} / 2$ is used as the input voltage, and the output sound pressure generated by the CMUT micro-unit contains not only the signal with frequency $\mathrm{f}_{\mathrm{s}}$, but also the harmonic signal of other different orders. The filtering, signal 
Fig. 29 The output sound pressure power spectrum corresponding to the AC signals of different period number as $\mathrm{V}_{\mathrm{DC}}=0$. a Normalized linear power spectrum. b Normalized logarithmic power spectrum

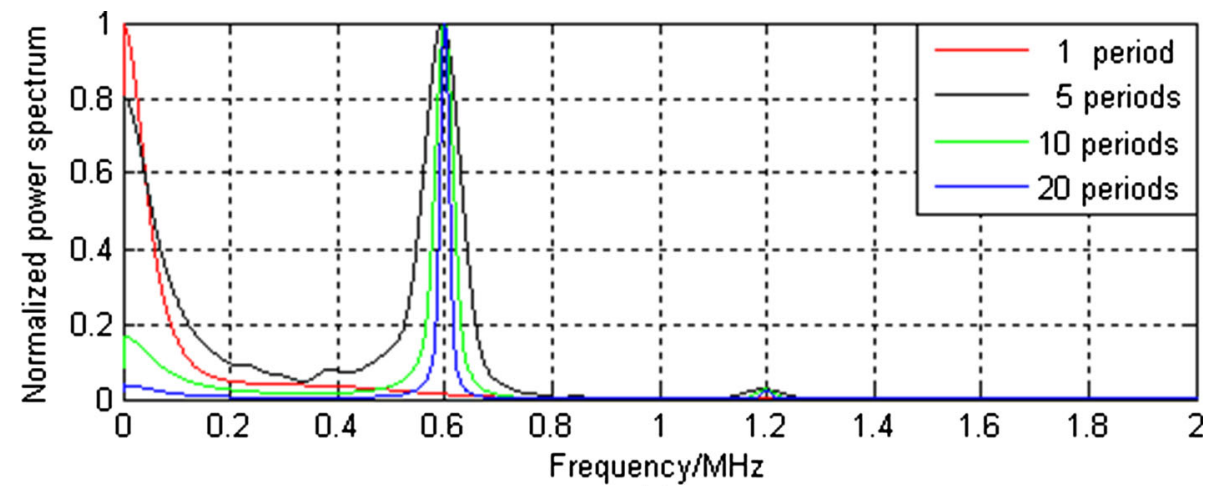

(a)

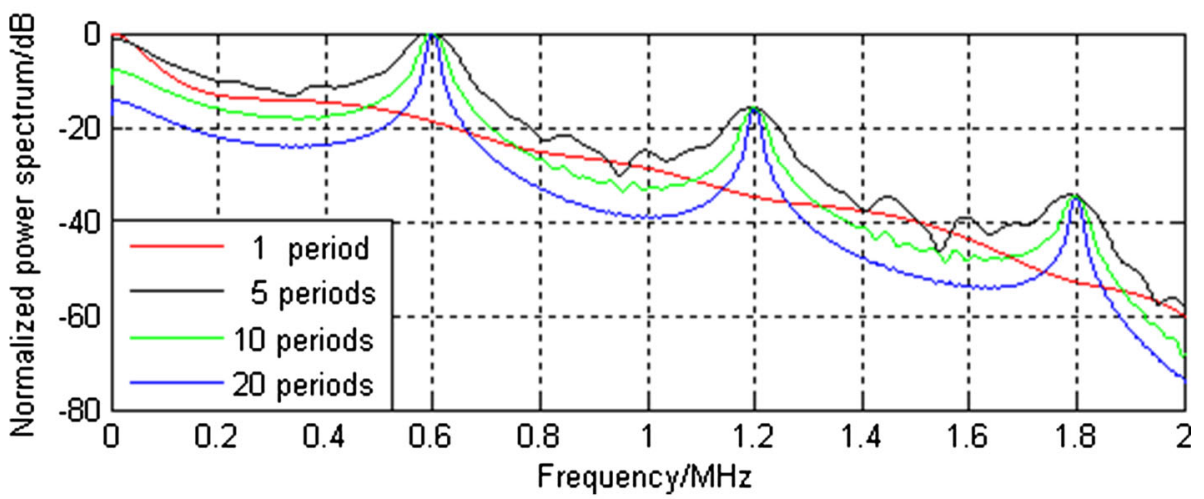

(b) compensation and other effective measures must be taken to suppress this nonlinear phenomenon to further improve the image quality.

4. With the increase of the period number, the duration of the vibration displacement and the output sound pressure becomes longer and the attenuation becomes slower. Its effective bandwidth gradually becomes narrow, and its harmonic components become more and more evident.

Therefore, in practical applications, it is necessary to select reasonably the DC bias voltage, the parameters of the AC input signal such as amplitude, frequency and period number combined with specific circumstances, in order to obtain high-quality test results.

Acknowledgements The authors wish to thank the Special Fund Support of the Shanxi Province Natural Science Foundation (201701D121066); the open project of Key Laboratory of Mcro Optoelectro Mechanical System Technology, Tianjin University, Ministry of Education; the open project of Key Laboratory of Dynamic Measurement (North University of China), Ministry of Education, North University of China; the Major State Basic Research Development Program of China (2016YFC0101900), the Fund for Shanxi '1331 Project' Key Subject Construction (1331KSC).

Author contributions All work with relation to this paper has been accomplished by all authors' efforts. The idea was proposed by HW. The state equation is deduced and the analysis model is established in
SIMULINK environment by HW and XW. The CMUT structure was designed by $\mathrm{CH}$. CX gave significant guidance in the analysis.

\section{Compliance with ethical standards}

Conflict of interest The authors declare that there is no conflict of interest.

Open Access This article is distributed under the terms of the Creative Commons Attribution 4.0 International License (http://creative commons.org/licenses/by/4.0/), which permits unrestricted use, distribution, and reproduction in any medium, provided you give appropriate credit to the original author(s) and the source, provide a link to the Creative Commons license, and indicate if changes were made.

\section{References}

Bhuyan A, Choe JW, Lee BC, Wygant IO, Nikoozadeh A, Oralkan Ö, Khuri-Yakub BT (2013) Integrated circuits for volumetric ultrasound imaging with 2-D CMUT arrays. IEEE Trans Biomed Circuits Syst 7:796-804

Certon D, Teston F, Patat F (2005) A finite difference model for cMUT devices. IEEE Trans Ultrason Ferroelectr Freq Control 52:2199-2210

Fouan D, Bouakaz A (2016) Investigation of classical pulse sequences for contrast-enhanced ultrasound imaging with a cMUT probe. IEEE Trans Ultrason Ferroelectr Freq Control 63:1496-1504

Greenlay BA, Zemp RJ (2017) Fabrication of linear array and toporthogonal-to-bottom electrode CMUT arrays with a sacrificial 
release process. IEEE Trans Ultrason Ferroelectr Freq Control 64:93-107

Koymen H, Atalar A, Aydoğdu E, Kocabaş C, Oğuz HK, Olcum A, Ozgurluk A, Unlugedik A (2012) An improved lumped element nonlinear circuit model for a circular CMUT cell. IEEE Trans Ultrason Ferroelectr Freq Control 59:1791-1799

Ladabaum I, Jin X, Soh HT, Atalar A, Khuri-Yakub BT (1998) Surface micromachined capacitive ultrasonic transducers. IEEE Trans Ultrason Ferroelectr Freq Control 45:2426-2439

Legros M, Novell A, Bouakaz A, Férin G, Dufait R, Certon D (2011) Tissue harmonic imaging with CMUTs. IEEE Int Ultrason Symp Proc 2011:2249-2252

Levent Degertekin F, Guldiken RO, Karaman M (2006) Annular-ring CMUT arrays for forward-looking IVUS: transducer characterization and imaging. IEEE Trans Ultrason Ferroelectr Freq Control 53:474-482

Lohfink A, Eccardt P-C (2005) Linear and nonlinear equivalent circuit modeling of CMUTs. IEEE Trans Ultrason Ferroelectr Freq Control 51:2163-2172

Nikoozadeh A, Oralkan Ö, Gencel M, Choe JW, Stephens DN, de la Rama A, Chen P, Thomenius K, Dentinger A, Wildes D, Shivkumar K, Mahajan A, O’Donnell M, Sahn D, Khuri-Yakub PT (2009) Forward-looking volumetric intracardiac imaging using a fully integrated CMUT ring array. IEEE Int Ultrason Symp Proc 2009:511-514

Novell A, Legros M, Felix N, Bouakaz A (2009) Exploitation of capacitive micromachined transducers for nonlinear ultrasound imaging. IEEE Trans Ultrason Ferroelectr Freq Control 56:2733-2743
Oralkan Ö, Ergun AS, Johnson JA, Karaman M, Demirci U, Kaviani K, Lee TH, Khuri-Yakub BT (2002) Capacitive micromachined ultrasonic transducers: next-generation arrays for acoustic imaging? IEEE Trans Ultrason Ferroelectr Freq Control 49:1596-1610

Satir S, Zahorian J, Degertekin FL (2013) A large-signal model for CMUT arrays with arbitrary membrane geometry operating in non-collapsed mode. IEEE Trans Ultrason Ferroelectr Freq Control 60:2426-2439

Sautto M, Savoia AS, Quaglia F, Caliano G, Mazzanti A (2017) A comparative analysis of CMUT receiving architectures for the design optimization of integrated transceiver front ends. IEEE Trans Ultrason Ferroelectr Freq Control 64:826-838

Wang H, Wang X, He C, Xue C (2014) Design and performance analysis of capacitive micromachined ultrasonic transducer linear array. Micromachines 5:420-431

Wong SH, Kupnik M, Butts-Pauly K, Khuri-Yakub BT (2007) Advantages of capacitive micromachined ultrasonics transducers (CMUTs) for high intensity focused ultrasound (HIFU). IEEE Ultrason Symp 2007:1313-1316

Wygant IO, Kupnik M, Khuri-Yakub BT (2008) Analytically calculating membrane displacement and the equivalent circuit model of a circular CMUT cell. IEEE Int Ultrason Symp Proc 2008:2111-2114

Yaralioglu GG, Ergun AS, Khuri-Yakub BT (2005) Finite-element analysis of capacitive micromachined ultrasonic transducers. IEEE Trans Ultrason Ferroelectr Freq Control 52:2185-2198 